Gülcher et al. (2020)

\title{
Corona structures driven by plume-lithosphere interactions and evidence for ongoing plume activity on Venus
}

\author{
Nature Geoscience 13, 547-554 (2020) \\ https://doi.org/10.1038/s41561-020-0606-1
}

\begin{abstract}
Anna J. P. Gülcher*1, Taras V. Gerya ${ }^{1}$, Laurent G. J. Montési ${ }^{2}$ and Jessica Munch ${ }^{1}$.
${ }^{1}$ Institute of Geophysics, ETH Zürich, Department of Earth Sciences, ETH Zürich, Switzerland

${ }^{2}$ Department of Geology, University of Maryland, College Park, USA
\end{abstract}

(Note: this is a post-print of the article published in Nature Geoscience) 


\title{
Corona structures driven by plume-lithosphere interactions and evidence for ongoing plume activity on Venus
}

\author{
Anna J. P. Gülcher*1, Taras V. Gerya ${ }^{1}$, Laurent G. J. Montési ${ }^{2}$ and Jessica Munch ${ }^{1}$. \\ ${ }^{1}$ Institute of Geophysics, ETH Zürich, Department of Earth Sciences, ETH Zürich, Switzerland \\ ${ }^{2}$ Department of Geology, University of Maryland, College Park, USA
}

In the absence of global plate tectonics, mantle convection and plume-lithosphere interaction are the main drivers of surface deformation on Venus. Among documented tectonic structures, circular volcano-tectonic features known as coronae may be the clearest surface manifestations of mantle plumes and hold clues to the global Venusian tectonic regime. Yet, the exact processes underlying coronae formation and the reasons for their diverse morphologies remain controversial. Here, we use 3D thermomechanical numerical simulations of impingement of a thermal mantle plume upon the Venusian lithosphere to assess the origin and diversity of large Venusian coronae. The ability of the mantle plume to penetrate into the Venusian lithosphere results in four main outcomes: lithospheric dripping, short-lived subduction, embedded plume and plume underplating. During the first three scenarios, plume penetration and spreading induce crustal thickness variations that eventually lead to a final topographic isostasy-driven topographic inversion from circular trenches surrounding elevated interiors to raised rims surrounding inner depressions, as observed on many Venusian coronae. Different corona structures may represent not only different styles of plume-lithosphere 
interactions, but also different stages in evolution. A morphological analysis of large existing coronae leads to the conclusion that least 37 large coronae (including the largest Artemis corona) are active, providing evidence for widespread ongoing plume activity on Venus.

The planet Venus presents a clear contrast of tectonic activity with the Earth, despite broadly similar interior structure and composition. Perhaps due to a water-depleted interior ${ }^{1,2}$ and high surface temperatures ${ }^{3,4}$, Venus does not feature Earth-like plate tectonics at present. Instead, its global-scale topographic characteristics and variety of tectonic and volcanic features ${ }^{5}$ can be attributed to underlying mantle convective and plume-lithosphere interaction processes $^{6,7,8}$. Whether Venus is geologically active today, and to what extent surface tectonics reflect the current state of the planet's interior, remains in question. The apparent young surface age of Venus and randomly distributed impact craters on the planet, initially ascribed as resulting from a global resurfacing event 500-700 Myr ago 9,10,11, can also be explained by equilibrium processes, suggestive of ongoing regional resurfacing ${ }^{12,13}$. Moreover, sites with thin elastic lithospheres and great apparent depths of compensation are suggestive of currently high heat flows and broad topographic uplifts of active mantle plumes ${ }^{14,15,16,17}$. In addition, active "hotspots" have been identified, where Venus has recently been resurfaced ${ }^{16,18,19,20}$. Individual lava flows may be just a few years old ${ }^{21}$.

We propose that the morphology of coronae can be used to reveal the location of recently active plumes. Coronae are characteristic quasi-circular volcano-tectonic features that are abundant on the Venusian surface (>500) and generally associated with volcanism, topographic relief and concentric or radial faulted patterns (Fig. 1, left panels) ${ }^{20,22,23}$. They feature a wide range of sizes ( 60 to $>1000 \mathrm{~km}$ ) and morphologies but typically display an annulus of closely spaced concentric fractures and/or ridges superimposed on a raised rim, with a central topography ranging from domes to plateaus to depressions ${ }^{23}$. Coronae are commonly understood as a response to crustal stresses developed above an upwelling mantle plume, followed by gravitational relaxation or collapse due to magma withdrawal $20,22,23,25,26,27,28,29$, 
possibly involving delamination of the lower crust $^{22,24}$. Some coronae exhibit tectonic structures at their margin suggestive of the incipient stages of subduction $30,31,32$.

Observables on Venus, such as topography, gravity, tectonics and volcanism, are limited in terms of their spatial-temporal resolution and global extent. Therefore, validations of coronae evolution scenarios rely on the exploration of numerical and/or analogue models, and subsequent comparison thereof with observables. Previous numerical models featured various corona-forming mechanisms such as lithospheric delamination surrounding plume up- or downwellings $\mathbf{s}^{22,24,26}$, Rayleigh-Taylor instabilities ${ }^{33,34}$, volcanic loading ${ }^{35}$ and pressure release melting ${ }^{36}$, while analogue models demonstrated the importance of plume-induced subduction ${ }^{32}$. Yet, many of these numerical models fail to address the voluminous magmatism observed at many coronae $22,24,28,33,34,35$ or the formation of a fractured anulus $28,33,34$. The annulus is easily explained with models featuring volcanic loading ${ }^{35}$ or caldera collapse ${ }^{27}$, but these cannot explain evidence for subduction. Moreover, the only three-dimensional numerical study of plumeinduced novae/coronae formation at present addresses merely a small range of corona dimensions (diameter $<150 \mathrm{~km})^{26}$. Any favorable corona-formation model should include several key corona features: (1) the variety of topographic reliefs observed; (2) annular tectonics and faulting and (3) magmatism/volcanism. At present, plume-lithosphere interaction models dominate in meeting these requirements. We present here a systematic 3D numerical study of plume-lithosphere interaction that links the diversity of large corona morphologies to lithospheric structure and provide guidance for identifying which coronae are currently active. The morphology of at least thirty-seven coronae are consistent with present-day activity (Fig. 2, Suppl. video 1).

\section{Thermomechanical simulations}

We ran 3D high-resolution magmatic-thermomechanical plume-lithosphere interaction models in a Venus-like environment (Methods, Extended Data Fig. 2, Table 1). We systematically varied plume size and temperature ${ }^{37}$, the lithospheric strength, i.e. lithospheric thickness ${ }^{38}$ and the intensity of magmatic weakening (see Methods). In addition, we varied the crustal thickness 
in the models since estimates vary on Venus ${ }^{14,39,40}$. Results of the numerical experiments (Extended Data Table 2) show systematic development of corona-like structures and reveal four regimes of plume-lithosphere interaction: (i) lithospheric dripping, (ii) ephemeral subduction, (iii) embedded plume and (iv) plume underplating. As summarized in Figure 3, these regimes are strongly dependent on plume buoyancy and the lithospheric and crustal configuration.

Figure 4 presents the four-stage evolution of a representative model for the first regime. Four evolution stages can be identified. During the first stage (Fig. 4a), the overlying mantle rheologically weakens by the plume-derived melts and allows the plume to rise towards the surface. Decompression melting of the rising mantle results in lower-crustal intrusions and volcanism in the corona interior. Increased temperatures and lithospheric thinning trigger the development of an uplifted crustal dome atop the circular plume head. At the second stage (Fig. 4b), the entire plume penetrates through the lithosphere, resulting in a circular lithospheric window occupied by plume material. The central uplift grows in amplitude. Relatively colder, denser crustal and lithospheric material at the plume margins is pushed outwards and downwards by the advancing plume material, producing an outer rise surrounding a deep trench and a still elevated interior. In the third stage (Fig. 4c), the plume spreads radially outwards, thereby broadening the developing corona structure at the surface. The crust and lithospheric mantle initially located above the plume are further displaced and thickened. Being rheologically weak, they form a viscous lithospheric drip at the plume margins. The corresponding topographic relief is characterized by a deep annular trough and an elevated interior that slowly loses its elevation. As crustal material is brought to greater depths and is subjected to higher temperatures, it densifies due to the basalt to eclogite phase change (Methods, Extended Data Fig. 3). The relatively young (40 Myr) and warm lithosphere in this model is too weak to prevent delamination and the drips repeatedly break off and sink into the lower mantle. The final stage (Fig. 4d) is characterized by plume activity decay and subsequent cooling of the lithosphere and solidification of partially molten crust. The isostatic response to the plume-induced crustal thickness variations leads to a final topographic inversion, where the trench, formed above the thickened crustal ring atop the lithospheric drip, is inverted into a raised corona rim. Similarly, 
the interior high, formed atop the area of removed lithosphere and thinned crust, gradually subsides into an inner depression.

When the same plume pierces through a lithosphere with a twice thinner crust (and hence lower moho temperatures, Figs. 5a-c), less basaltic material is transformed into eclogite. Instead of lithospheric drips, a radial subduction zone develops at the plume margin. This subduction zone is short-lived and followed by circular slab-detachment (Fig. 5b). The topographic evolution is similar to that of the reference lithospheric dripping model (Fig. 4), but bending of the lithosphere into down-dipping slabs produces an outer rise with higher amplitude. A similar subduction-like scenario is obtained in the model with an older (80-120 Myr) and thus colder lithosphere that promotes a more rigid behavior (models M10-M14 in Extended Data Table 2). Lithosphere rigidity results in one or several episodes of retreating subduction that may be focused towards a certain arc, and are always followed by segmented slab break-off. As in the case of lithospheric drips, these models eventually isostatically relax to form an inverted topographic profile with an outer rim and inner depression.

The ratio of plume buoyancy over lithospheric strength ${ }^{38,41}$ exerts a major control on plume penetration in the Venusian lithosphere (Methods, Fig. 3). When the lithosphere is sufficiently cold $\left(T_{\text {moho }}<1100 \mathrm{~K}\right)$ and the plume is not buoyant enough relative to the lithospheric strength (Buoyancy ratio $B r<4$ ), the plume cannot reach and pierce through the lithosphere but spreads laterally under it (plume underplating regime, Figs. $5 \mathrm{~d}-\mathrm{f}$ ). The lithosphere is thinned above the plume and the surface displays only a dome or plateau, without any rim or trench. Even after isostatic relaxation, the interior of the corona remains elevated. A transitional "embedded plume" regime was also detected in several experiments, in which the mantle plume partially penetrates the lithosphere but does not force crustal material to be recycled down into the mantle (Extended Data Fig. 4). The embedded plume induces magma emplacement in the 
crust followed by crustal flow, thereby resembling some of the mechanisms seen in prior smallscale crustal convection models of novae and coronae ${ }^{26}$.

Model limitations (Methods) prevent a detailed comparison with observed tectonic structures, which may also be influenced by fine-scale phenomena such as dike intrusion and elastic loading. Nevertheless, most of the models show surface strain-rate patterns consistent with concentric deformation structures at the corona margins (Extended Data Figure 5). In the most rigid models, stellate and radial surface deformation patterns can also be distinguished. Volcanism is present in all plume penetration models as newly-formed crust (volcanic material) is emplaced in the corona interior via melt percolation (Figs. 4, 5a-c and Extended Data Fig. 4).

\section{Morphological diversity of Venusian coronae}

The temporal evolution of the radially averaged topographic profiles for models representative of each regime shows how different corona morphologies not only represent different plume-lithosphere interactions, but also different stages in evolution (Fig. 6). Our models suggest that a penetrating plume is key for lithospheric dripping (high moho temperatures) or lithospheric subduction (low moho temperatures) at the plume margin, and for lithospheric thinning of the corona interior (Extended Data Fig. 6). The suction below the lithospheric drips or slabs and bending of the lithosphere creates a circular trench and an outer rise at the surface, that are inverted during the isostatic relaxation stage (Figs. 6a-b). In our models, coronae with rims and trenches are only produced by mantle plumes that at least partially penetrate into the Venusian lithosphere. Therefore, the common occurrence of coronae displaying rims ${ }^{24,25}$ suggests that most plumes that formed coronae were able to penetrate at least partially into the Venusian lithosphere. In addition, for coronae formed by a penetrating mantle plume, we are able to distinguish active from inactive structures: active coronae feature an outer trench and rise that imply ongoing suction above downwards-moving lithospheric material and an elevated interior supported by plume buoyancy, whereas inactive coronae show 
an inverted topographic profile of outer rim and inner depression linked to a thinned lithosphere (Fig. 6).

\section{Observational evidence for coronae activity}

Based on our models, we can assess the activity of individual coronae on Venus, assuming that mantle-lithosphere interactions are dominantly responsible for their formation. Most coronae formed in the numerical models range in diameter from 300 to $1000 \mathrm{~km}$ (Extended Data Table 2), encompassing a wide range of corona dimensions that are observed on Venus ${ }^{23,42}$. A direct comparison of the surface topography of representative coronae with those obtained in selected models is shown in Figure 1 and Extended Data Figure 7. Thouris Corona $\left(6.5^{\circ} \mathrm{S} ; 12.9^{\circ} \mathrm{E}\right)$ and Aruru Corona $\left(9.0^{\circ} \mathrm{S} 262^{\circ} \mathrm{E}\right)$ display raised rims surrounding lower elevations, features that mark later corona evolution stages, implying that the underlying plume is now inactive (Figs. 1bc). In contrast, the outer rise and deep trench displayed by Aramaiti Corona $\left(25.5^{\circ} \mathrm{S} 82^{\circ} \mathrm{E}\right.$, Fig. 1a) is evidence of lithospheric bending and suction above downgoing lithosphere, implying that the coronae is currently in an active stage that predates final isostatic relaxation into an inverted topographic profile. Based on these topographic characteristics, we suggest that the impressive Artemis corona $\left(25^{\circ} \mathrm{S}, 135^{\circ} \mathrm{E}\right)$ also hosts ongoing activity at its south-eastern margin (Extended Data Fig. 7), which is in agreement with former interpretations of slab-retreat at the corona $\operatorname{margin}^{29,30,31,43,44}$.

We evaluated the possibility of present-day corona activity by systematically analyzing the surface topography of large coronae (diameter $>300 \mathrm{~km}$ ) on Venus (see Methods for details regarding this analysis). A corona is labeled as currently "active" if it features a clear outer rise and trench, "inactive" if no outer rise but a rim and inner depression is evident, or "unclassified" if the presence of these features is ambiguous. The results of this global analysis are summarized in Fig. 2, Extended Data Fig. 1, Table 1 and Suppl. video 1. We found expressions of ongoing plume activity on thirty-seven coronae on Venus. Most of these coronae are located in Themis Regio $\left(40^{\circ} \mathrm{S}, 286^{\circ} \mathrm{E}\right)$ and near Lada Terra $\left(60^{\circ} \mathrm{S}, 20^{\circ} \mathrm{E}\right)$ and Alpha Regio $\left(22^{\circ} \mathrm{S}, 5^{\circ} \mathrm{E}\right)$. A few are in Eastern Eistla Regio $\left(15^{\circ} \mathrm{N}, 45^{\circ} \mathrm{E}\right)$ and southwest of the Aphrodite Terra (centered at $10^{\circ} \mathrm{S}, 100^{\circ} \mathrm{E}$ ). For 
thirty-five other coronae, the presence of an elevated rim with inner depression, in the absence of an outer rise, imply that the structure is currently inactive. Analysis of the remaining coronae in our database (61) was inconclusive, either because their topography was not well resolved by the dataset, presented ambiguous characteristics, or was markedly different from that in our models (Extended Data Table 1). Pre-existing crustal or lithospheric heterogeneities, or interaction with chasmata, might significantly affect otherwise simple, symmetrical corona structures. For coronae along Dali, Diana, and Hecate Chasmata, it cannot be ascertained that the trough results from plume-related subduction or chasma-related rifting. However, Atahensik Corona $\left(19^{\circ} \mathrm{S}, 170^{\circ} \mathrm{E}\right)$ and Miralaidji Corona $\left(14^{\circ} \mathrm{S}, 163.8^{\circ} \mathrm{E}\right)$ are considered active because of the clear trenches on their SE and $\mathrm{N}$ side, respectively.

Some of the coronae we classify as active are located at previously suggested hotspot locations ${ }^{16,18,19}$, yet our size restrictions (by numerical models as well as dataset resolution) limited this survey to a $\sim 40 \%$ of the Venusian coronae database ${ }^{45}$. Recent volcanism in Imdr and Dione Regiones was identified in the Visible and Infrared Thermal Imaging Spectrometer (VIRTIS) onboard Venus Express ${ }^{16}$. That high emissivity was associated with volcanoes, not coronae, as the VIRTIS resolution of $100 \mathrm{~km} / \mathrm{pixel}$ is insufficient to characterize the features discussed here. Three previously proposed hotspot regions have been described as "corona-dominated"19,46. Among these, Themis Regio features mainly active corona according to our study, including Semiramus $\left(293^{\circ} \mathrm{E}, 37^{\circ} \mathrm{S}\right)$, Tacoma $\left(37^{\circ} \mathrm{S}, 288^{\circ} \mathrm{E}\right)$ and Ukemochi $\left(39^{\circ} \mathrm{S}, 296^{\circ} \mathrm{E}\right)$ Coronae. In Eastern Eistla Regio, the large Ninmah $\left(16.5^{\circ} \mathrm{N}, 49^{\circ} \mathrm{E}\right)$ and Isong $\left(12^{\circ} \mathrm{N}, 49.5^{\circ} \mathrm{E}\right)$ Coronae show evidence of a trough along at least some of their perimeter, a sign of current activity, whereas other coronae are interpreted to be inactive or inconclusive. Several coronae in the Eastern Eistla Regio as well as in the Central Eistla Regio $\left(10^{\circ} \mathrm{N}, 15^{\circ} \mathrm{E}\right)$ display ambiguous features. For example, Sappho, Pavlova $\left(14.5^{\circ} \mathrm{N}, 39.5^{\circ} \mathrm{E}\right)$ and Didilia $\left(18.5^{\circ} \mathrm{N}, 37.5^{\circ} \mathrm{E}\right)$ Coronae were classified as having a rim and a raised interior and show fairly recent volcanic flows ${ }^{19,46}$, which would be consistent with current activity, but lack the topographic trench characteristics of dripping or subducting lithosphere (Extended Data Table 1). Lada Terra, where many of our active coronae are located, and Quetzalpetlatl Corona $\left(68^{\circ} \mathrm{S}, 357^{\circ} \mathrm{E}\right)$ have previously been proposed sites of recent volcanic 
activity $^{48}$. Moreover, many of the identified raised novae ${ }^{49}$ fall within zones of proposed activity (pink stars in Extended Data Fig. 1), consistent with the suggestion that these are structures caused by presently active mantle plumes ${ }^{26}$.

The temporal evolution of the effective surface heat flow (see Methods) of modelled coronae is shown in Extended Data Figure 8. Peak heat flow reaches $~ 500-600 \mathrm{~mW} / \mathrm{m}^{2}$ (plume penetrating regimes), $\sim 200 \mathrm{~mW} / \mathrm{m}^{2}$ (embedded plume regime), or $\sim 50 \mathrm{~mW} / \mathrm{m}^{2}$ (for underplated plume), but decreases significantly following peak activity. A recent study ${ }^{17}$ found elevated surface heat flow at several coronae of $20-300 \mathrm{~mW} / \mathrm{m}^{2}$, far exceeding the estimated average for Venusian surface $\left(\sim 40 \mathrm{~mW} / \mathrm{m}^{2}\right)$. Heat flow in our models is consistent with these coronae being slightly pas their peak activity period, or previous estimates of coronae heat flow underestimating their contribution to heat flow on the planet ${ }^{17}$.

\section{Venus' global geodynamics}

Our study presents new evidence for recent tectonic and magmatic activity on the surface of Venus, complementing other indications of such activity ${ }^{16,19,21,31,44}$. The typical model evolution time in our experiments, measuered from rising plume to fully cooled and recrystallized plume material, is only a few tens of millions of years (20-55 Myr). Considering timeunderestimating model limitations (Methods), a maximum age of several tens of millions of years is appropriate for active coronae on Venus. Coronae activity spanning the majority of surface ages, from the earliest plains to present day, implies a gradual resurfacing behavior of Venus, akin to Earth-like volcanic and interior processes ${ }^{12,13}$, not the episodic resurfacing previously proposed for Venus ${ }^{9,10,11}$.

The global arrangement of active coronae suggests a large-scale organization of tectonomagmatic activity on the planet, with an broad active region covering Themis, Lada terra and Alpha Regio contrasting with regions where large active coronae are absent (around Beta and Phoebe Regiones). This distribution of plume activity is enigmatic and may be crucial to address in future studies. It also reflects the importance of lithosphere structures: a thin lithosphere (high buoyancy ratio) leads to easy plume penetration through the lithosphere and subsequent corona 
formation. If regions of thin elastic lithospheric thickness ${ }^{14}$ such as the Themis, Alpha and Eistla Regio, also have thin thermal lithospheres, they would be particularly prone to plume penetration. Indeed, several of our identified locations of enhanced activity also feature thin elastic thicknesses (Fig.2). Conversely, almost no (active) coronae are identified within the hightopography regions of the Aphrodite and Ishtar Terra. A low apparent elastic thickness there may indicate isostatic compensation, not thin thermal lithosphere ${ }^{14,15}$.

So far, we have been able to ascertain ongoing activity or inactivity for relatively few coronae on Venus. This is due not only to the dimensions and resolution of our numerical models (Methods), but also to the scarcity of high-resolution topography data ("Poorly resolved" coronae in Extended Data Table 1). Improvements upon numerical techniques and resolution are needed to allow for better comparisons with different types of datasets (such as gravity, heat emission, lava flows and imagery). Furthermore, any future mission that would collect more and higher resolution topographic and geodynamic data of the planet would help further determine the activity of coronae and other geological/volcanic features, significantly contributing new understanding of the interior dynamics of Venus and the evolution of terrestrial planets in general. Our suggested regions of extensive recent corona activity may serve as interested target for detail investigation by future spacecraft missions.

\section{Methods}

Full details on the employed methodology, including statements of data availability and any associated references, are available in the online version of the paper. 


\section{REFERENCES}

1. Elkins-Tanton, L. T., Smrekar, S. E., Hess, P. C., \& Parmentier, E. M. Volcanism and volatile recycling on a one-plate planet: Applications to Venus. Journal of Geophysical Research E: Planets 112, E04S06 (2007)

2. Huang, J., Yang, A., \& Zhong, S. Constraints of the topography, gravity and volcanism on Venusian mantle dynamics and generation of plate tectonics. Earth and Planetary Science Letters 362, 207-214 (2013).

3. Crameri, F., \& Kaus, B. J. P. Parameters that control lithospheric-scale thermal localization on terrestrial planets. Geophysical Research Letters 37, L09308 (2010)

4. Bercovici, D. and Ricard, Y. Plate tectonics, damage and inheritance. Nature 508, 513- 516 (2014).

5. Solomon, S. C. et al. Venus tectonics: An overview of Magellan observations. Journal of Geophysical Research 97(E8), 13199-13255 (1992)

6. Kaula, W. M. Venus: A contrast in evolution to earth. Science 247(4947), 1191-1196 (1990)

7. Phillips, R. J. Convection-Driven Tectonics on Venus. Journal of Geopysical Research 95, 1301-1316 (1990).

8. Wieczorek, M. A. Gravity and Topography of the Terrestrial Planets. Treatise on Geophysics: Second Edition (Vol. 10), 153-193 (Elsevier B.V., Oxford,2015)

9. Turcotte, D. L. An episodic hypothesis for Venusian tectonics. Journal of Geophysical Research 98(E9), 17061 (1993).

10. Strom, R. G., Schaber, G. G., \& Dawson, D. D. The global resurfacing of Venus. Journal of Geophysical Research 99(E5), 10899-10926 (1994).

11. Romeo, L. Monte Carlo models of the interaction between impact cratering and volcanic resurfacing on Venus: the effect of the Beta-Atla-Themis anomaly. Planetary and Space Science 87, 157-172 (2013) 
12. Herrick, R. R., \& Rumpf, M. E. Postimpact modification by volcanic or tectonic processes as the rule, not the exception, for Venusian craters. Journal of Geophysical Research 116, E02004 (2011)

13. Bjonnes, E.E., Hansen, V.L., James, B. \& Swenson, J.B. Equilibrium resurfacing of Venus: Results from new Monte Carlo modeling and implications for Venus surface histories. Icarus 217, 451-461 (2012)

14. Simons, M., Solomon, S.C. \& Hager, B. H. Localization of gravity and topography: constraints on the tectonics and mantle dynamics of Venus. Geophys. J. Int. 131, 24-44 (1997)

15. Anderson, F. S., \& Smrekar, S. E. Global mapping of crustal and lithospheric thickness on Venus. Journal of Geophysical Research 111, E08006 (2006)

16. Smrekar, S. E. et al. Recent hotspot volcanism on Venus from VIRTIS emissivity data. Science 328, 605-608 (2010).

17. O'Rourke, J.G. and Smrekar, S. Signatures of lithospheric flexure and elevated heat flow in stereo topography at coronae on Venus. Journal of Geophysical research 123, 369-389 (2018)

18. Phillips, R. J., Grimm, R. E., \& Malin, M. C. (1991). Hot-Spot Evolution and the Global Tectonics of Venus. Science, 252, 651 LP-658 (1991)

19. Stofan, E.R., Smrekar, S.E. Bindschadler, D.L. \& Senske, D. Large topographic rises on Venus: Implications for mantle upwellings, J. Geophys. Res. 100, 23,317-23,327 (1995)

20. Stofan, R., Sharfron, V. L., Baer, G., Bindschadler, L., Janes, D. M., and Squyres, W. (1992). Global distribution and characteristics of coronae and related features on Venus: Implications for origin and relation to mantle processes. Journal of Geophysical Research 97, $13,347-13,378$ (1992)

21. Filiberto J., Trang, D., Treiman, A.H. \& Gilmore, M.S. Present-day volcanism on Venus as evidenced from weathering rates of olivine. Science Advances 6, eaax7445 (2020)

22. Stofan, E. R., Bindschadler, D. L., Head, J. W., \& Parmentier, E. M. Corona structures on Venus: Models of origin. Journal of Geophysical Research 96, 20,933-20,946 (1991) 
23. Roberts, K. and Head, J. W. Large scale volcanism associated with coronae on Venus: implications for formation and evolution. Geophysical Research Letters 20, 1111-1114 (1993).

24. Smrekar, S. E. and Stofan, E. R. Corona Formation and Heat Loss on Venus by Coupled Upwelling and Delamination. Science 277, 1289-1294 (1997)

25. Grindrod, P. M. and Hoogenboom, T. Venus: The corona conundrum. Astronomy \& Geophysics 47, 3.16-3.21 (2006).

26. Gerya, T. V. Plume-induced crustal convection: 3D thermomechanical model and implications for the origin of novae and coronae on Venus. Earth Planet. Sci. Lett. 391, 183192 (2014).

27. Lang, N.P. and López, I. The magmatic evolution of three Venusian coronae. From: Platz, T., Massironi, M., Byrne, P. K. \& Hiesinger, H. (eds). Volcanism and Tectonism across the Inner Solar System (Geological Society London, Special Publications, 401, 77-95, 2015)

28. Janes, D.M., \& Squyres, S.W. (1995) Viscoelastic relaxation of topographic highs on Venus to produce coronae. Journal of Geophysical Research 100, 21,173-21,187 (1995).

29. Janes, D.M., et al. Geophysical models for the formation and evolution of coronae on Venus. Journal of Geophysical Research 97, 16,055-16,067 (1992)

30. McKenzie, D. et al. Features on Venus generated by plate boundary processes. Journal of Geophysical Research 97, 13,533-13,544 (1992)

31. Sandwell, D. T., \& Schubert, G. Evidence for retrograde lithospheric subduction on Venus. Science 257, 766-770 (1992)

32. Davaille, A., Smrekar, S. E., \& Tomlinson, S. Experimental and observational evidence for plume-induced subduction on Venus. Nature Geoscience 10, 349-355 (2017)

33. Piskorz, D., Elkins-Tanton, L. T. \& Smrekar, S. E. Coronae formation on Venus via extension and lithospheric instability. J. Geophys. Res. 119, 2568-2582 (2015).

34. Hoogenboom, T. \& Houseman, G. A. Rayleigh-Taylor instability as a mechanism for corona formation on Venus. Icarus 180, 292-307 (2006). 
35. McGovern, P.J., Rumpf, M.E. and Zimbelman, J.R. The influence of lithospheric flexure on magma ascent at large volcanoes on Venus. Journal of Geophysical Research 118, 24232437 (2013)

36. Dombard, A. J., Johnson, C. L., Richards, M. A. \& Solomon, S. C. A magmatic loading model for coronae on Venus. J. Geophys. Res. 112, E04006 (2007).

37. Burov, E., \& Cloetingh, S. Controls of mantle plumes and lithospheric folding on modes of intraplate continental tectonics: Differences and similarities. Geophysical Journal International, 178, 1691-1722 (2009)

38. Baes, M., Gerya, T., \& Sobolev, S. V. 3-D thermo-mechanical modeling of plume-induced subduction initiation. Earth and Planetary Science Letters 453, 193-203 (2016)

39. James, P. B., Zuber, M. T., \& Phillips, R. J. Crustal thickness and support of topography on Venus. Journal of Geophysical Research 118, 859-875 (2013)

40. Jiménez-Díaz, A. et al. Lithospheric structure of Venus from gravity and topography. Icarus 260, 215-231 (2015)

41. Ueda, K., Gerya, T., \& Sobolev, S. V. Subduction initiation by thermal-chemical plumes: Numerical studies. Physics of the Earth and Planetary Interiors 171, 296-312 (2008)

42. Stofan, E. R., Smrekar, S. E., Tapper, S. W., Guest, J. E., \& Grindrod, P. M. Preliminary analysis of an expanded corona database for Venus. Geophysical Research Letters 28, 42674270 (2001)

43. Brown, C. D., \& Grimm, R. E. Lithospheric rheology and flexure at Artemis Chasma, Venus. Journal of Geophysical Research 101, 12697-12708 (1996)

44. Zampa, L.S., Tenzer, R., Eshagh, M. \& Pitonak, M. Evidence of mantle upwelling/downwelling and localized subduction on Venus from the body-force vector analysis. Planetary and Space Science 157, 48-62 (2018)

45. USGS Astrogeologicy Science Centre, Gazeteer for Planetary Nomenclature https://planetarynames.wr.usgs.gov/SearchResults?target=VENUS\&featureType=Corona,\% $\underline{20 \text { coronae }}$ 
46. Smrekar, S. E., \& Stofan, E. R. Origin of Corona-Dominated Topographic Rises on Venus. Icarus 139, 100-115 (1999)

47. Sandwell, D. T. (2015). Venus: https://topex.ucsd.edu/pub/sandwell/google/venus

48. Ivanov, M. A. and Head, J. W. The Lada Terra rise and Quetzalpetlatl Corona: A region of long-lived mantle upwelling and recent volcanic activity on Venus. Planetary and Space Science 14-15, 1880-1894 (2010)

49. Krassilnikov, A. S. and Head, J. W. Novae on Venus: Geology, classification and evolution. Journal of Geophysical Research 108, 5108 (2003)

50. Kereszturi, Á., Hoogenboom, T., Bleamaster, L. F., and Hargitai, H. Corona (Venus), 1-11. (Springer York, New York, NY, 2014)

51. Gülcher, A.J.P., Montési, L.G.V., Gerya, T.V. \& Munch, J. (2020) Venus coronae activity classification [Data set]. Zenodo. https://zenodo.org/record/3608692

52. Crameri, F. (2018) Scientific Colour Maps. Zenodo. http://doi.org/10.5281/zenodo.1243862

\section{Corresponding author}

Correspondence and requests for materials should be addressed to A.J.P. Gülcher (anna.guelcher@erdw.ethz.ch).

\section{Acknowledgements}

We thank the three anonymous reviewers, whose thoughtful and thorough reviews improved the quality of this manuscript significantly. This study was co-funded by the grant NASA NNX14AG51G (LM), SNF grant 200021_182069 (TG,JM) and EU project Subitop (JM). All simulations were performed on the ETH-Zurich Euler cluster. The open-source software ParaView (http://www.paraview.org) was used for 3D visualizations of the experiments. The perceptually uniform scientific colour map lapaz ${ }^{52}$ was used for Fig. 2 and Extended Data Fig. 1 to prevent visual distortion of the data. 


\section{Author contributions}

A. J. P. Gülcher designed the study, conducted the experiments, interpreted the numerical results and the natural data and prepared this manuscript. T. V. Gerya designed the study, designed the 3D thermomechanical code and interpreted the results. L. G. J. Montési initiated and designed the study, and interpreted the results and natural data. J. Munch contributed to the study design and conduction of the numerical experiments. All authors collaborated and contributed intellectually to this paper.

Additional information

Supplementary information is available in the online version of the paper. Reprints and permissions information is available online at www.nature.com/reprints.

Competing financial interests

The authors declare no competing financial interests. 
a

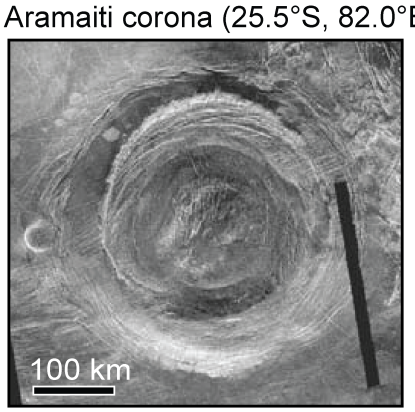

b Thouris corona $\left(6.5^{\circ} \mathrm{S}, 12.9^{\circ} \mathrm{E}\right)$

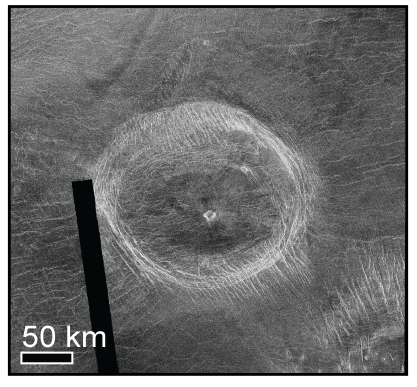

C Aruru corona $\left(9.0^{\circ} \mathrm{N}, 262.0^{\circ} \mathrm{E}\right)$

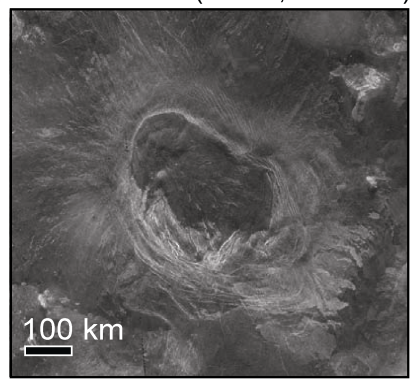

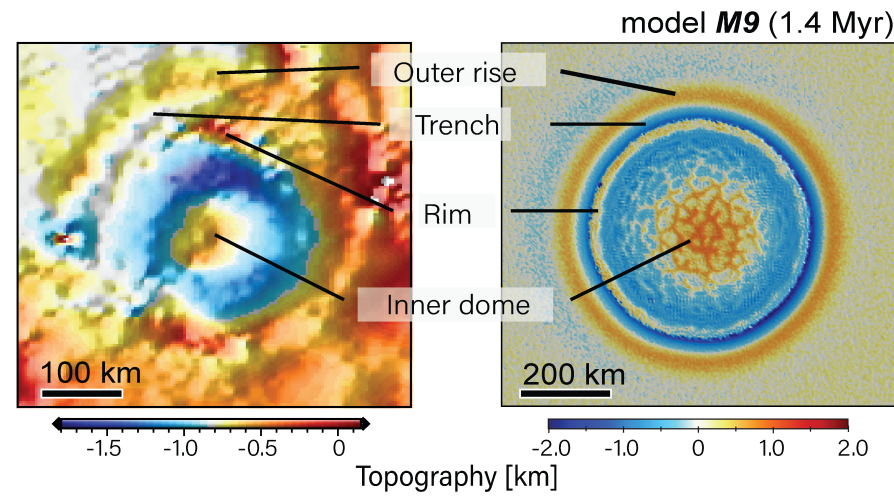
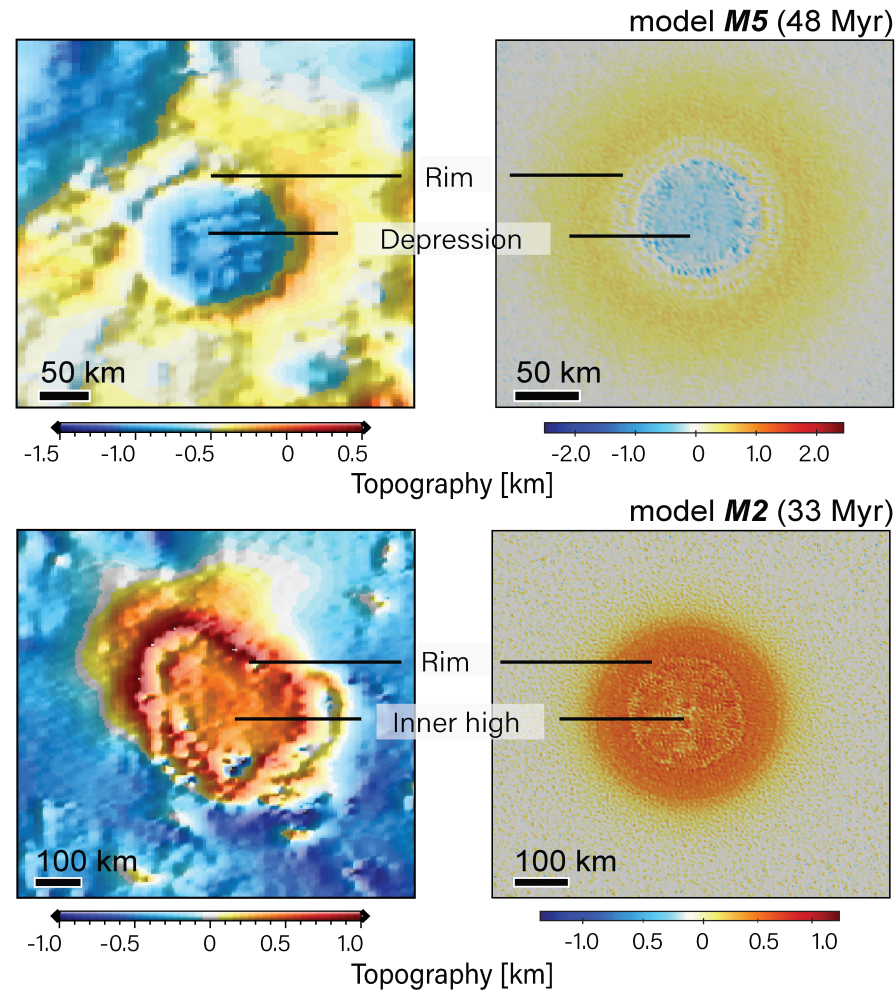

Figure 1 - Comparison of various corona morphologies on Venus with numerical simulations. Venusian coronae imaged by Synthetic Aperture Radar (left), their topographic signature (middle) and one of the numerical models which produced a similar topographic shape (right). Images from ref. 25 ( $a$ and c) and ref. 50 (b). Magellan data set from ref. 47. The topography is relative to $6051.877 \mathrm{~km}$. (a) Aramaiti corona, $25.5^{\circ} \mathrm{S} 82.0^{\circ} \mathrm{E}$ compared with numerical model M9 (1.4 Ma, classified as "ephemeral subduction"); (b)Thouris corona, $6.5^{\circ} \mathrm{S} 12.9^{\circ} \mathrm{E}$, compared with numerical model M5 (48 Ma, classified as "embedded plume"); (c) Aruru corona, 9.0 $\mathrm{N} 262^{\circ} \mathrm{E}$ compared with numerical model M2 (33 Ma, classified as "embedded plume"). 


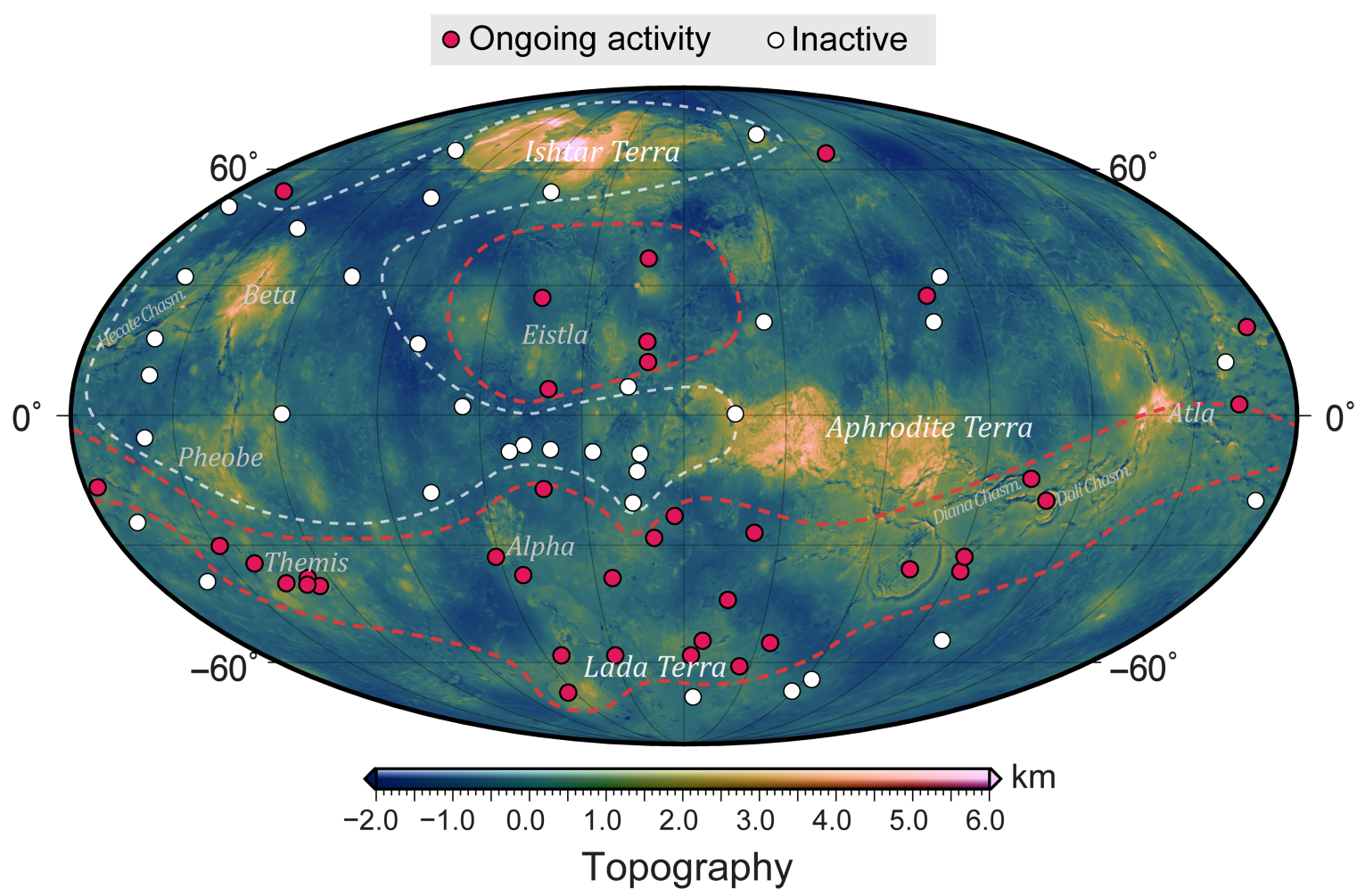

Figure 2 - Global distribution of coronae identified as inactive (white circles) or showing ongoing activity (red circles). The global topography 47 is relative to $6051.877 \mathrm{~km}$ and is plotted on a Mollweide projection centered at $60^{\circ} \mathrm{E}$ longitude. Nomenclature of key areas and chasmata are shown in light text. Coronae that were analyzed but could not be classified are shown in Extended Data Figure 1 and recorded in Supplementary Table 1. A KML file containing the location of each of the coronae is available in Gülcher et al. (2020) ${ }^{51}$. The dashed lines contour our proposed areas of focused plume activity (red) or inactivity (white). 


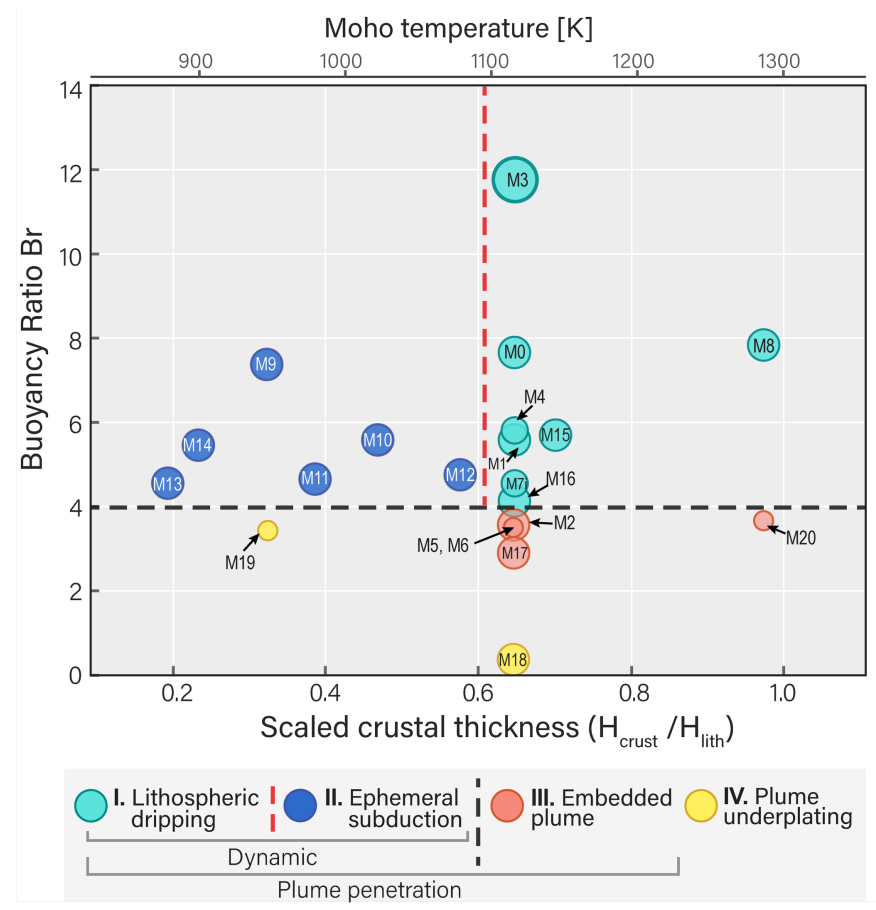

Figure 3-Summary of the numerical results and their dependence on the explored parameters. Regime diagram as a function of the Buoyancy ratio (non-dimensional ratio of the plume buoyancy and lithospheric strength, vertical axis) and the scaled crustal thickness (nondimensional ratio of crustal thickness over lithospheric thickness, horizontal axis). The scaled crustal thickness is analogous to the moho temperature (top axis). Each of the circles refers to one of the numerical experiments, and their relative sizes represent their relative initial plume size. The black line (Buoyancy ratio of 4) separates the dynamic plume penetration regimes (I and II) from the static regimes (III and IV), whereas the red line $\left(T_{\text {moho }}=1100 \mathrm{~K}\right)$ separates the lithospheric dripping from ephemeral subduction regime (for the latter, the presence of a subducting slab for $>0.25$ Myr is required). Note that a slight inclination of the red line may also be appropriate given the distribution of our models in the parameter space. 


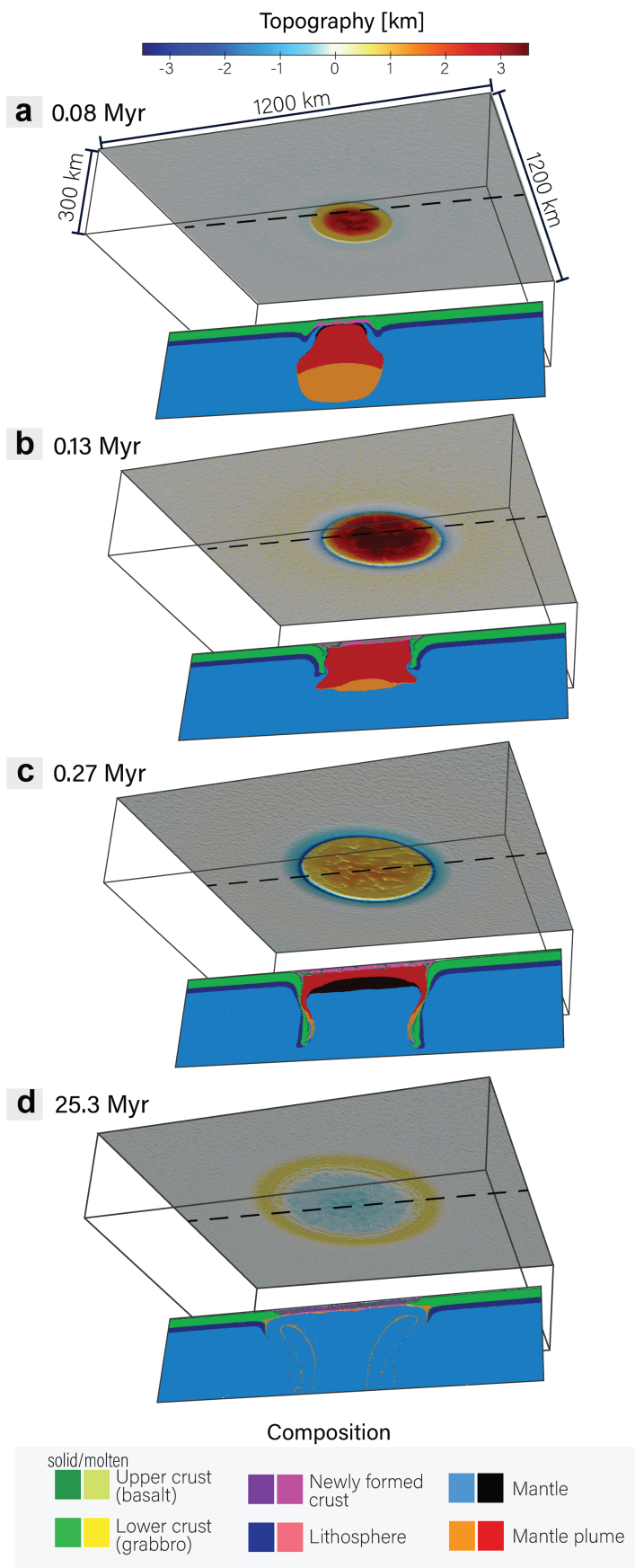

Figure 4 - Evolution of a corona-forming model involving plume-induced lithospheric delamination of a weak lithosphere (Model MO). Each panel includes a map of surface topography and a cross-section showing composition taken in the center of the model (dashed line). a) Rise of the buoyant mantle plume that penetrates into the lithosphere $(0.08 \mathrm{Myr})$; $\boldsymbol{b}$-c) 
Accepted manuscript: Gülcher et al. (2020), Nature Geoscience: https://doi.org/10.1038/s41561-020-0606-1

Radially spreading plume and lithospheric delamination at the plume margins, resulting in a trench surrounding an interior high (0.13 and 0.27 Myr, respectively); d) Lithosphere cooling and solidification of the plume and crust, leading to isostatic adjustment into an outer rim surrounding an interior depression (25.3 Myr). Model parameters are listed in Extended Data Table 2. 


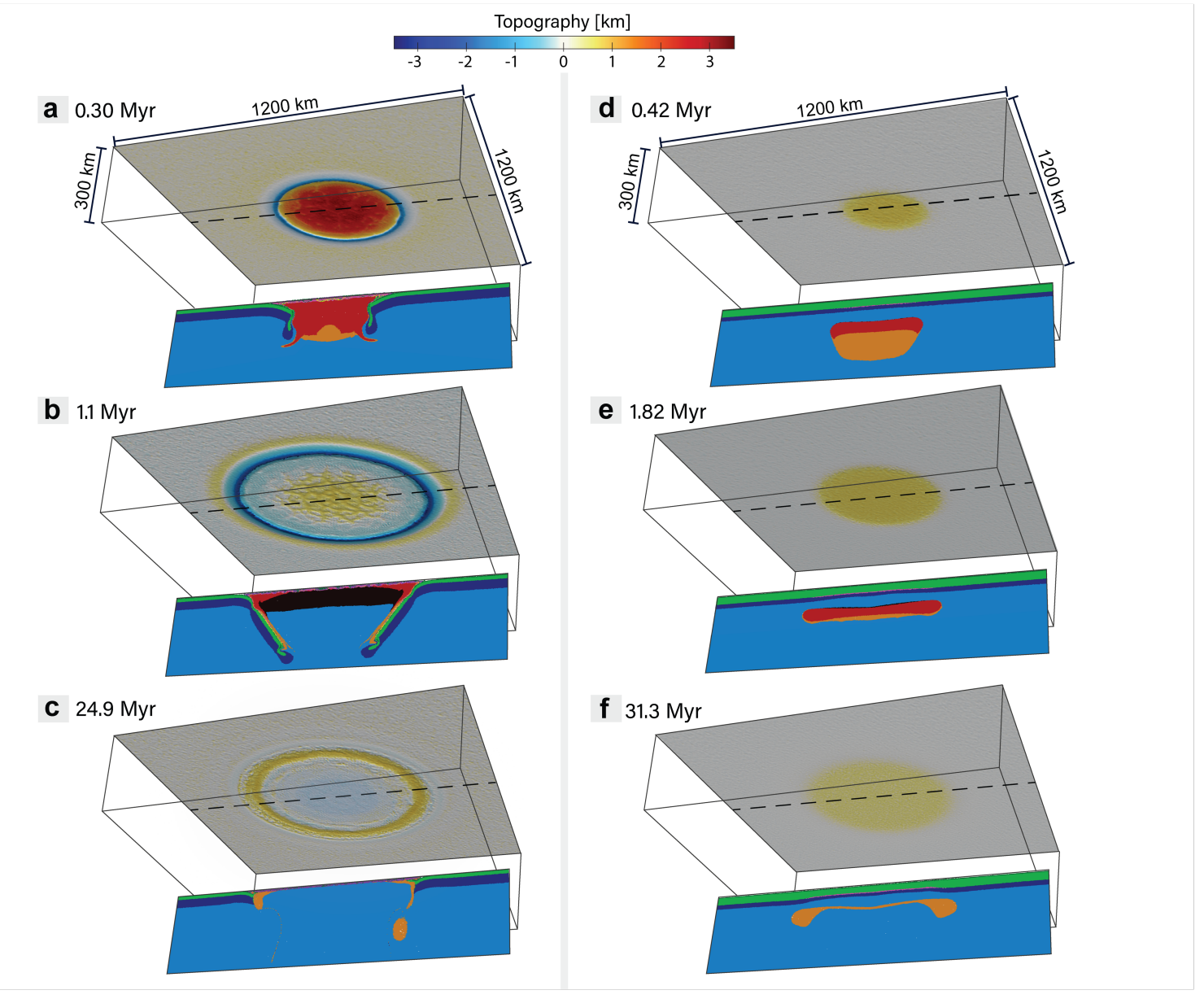

Figure 5 - Evolution of corona-forming models involving short-lived subduction (left, model M9) or plume underplating (right, model M18). Each image includes a map of surface topography and a cross-section showing composition taken in the center of the structure (dashed line, see legend in Fig. 4). a-b) Ephemeral radial subduction at the plume margins caused by the penetration of a buoyant mantle plume into a thinner crust (1.1 and 24.9 Myr) followed by c) topographic inversion (24.9 Myr); $d$-f) Plume underplating caused by insufficient magmatisminduced weakening of the strong plate (0.42; 1.82 and 31.3 Myr). The topography always features a dome without a depression or surrounding trench. Model parameters are listed in Extended Data Table 2. 
a regime $I$ - lithospheric dripping
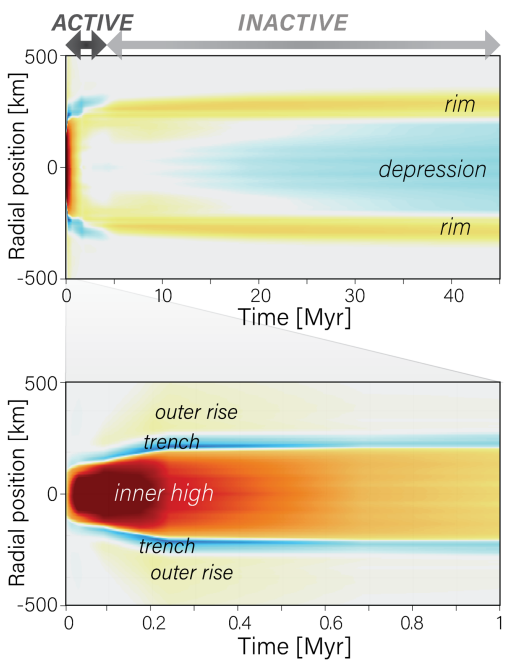

b regime II - ephemeral subduction
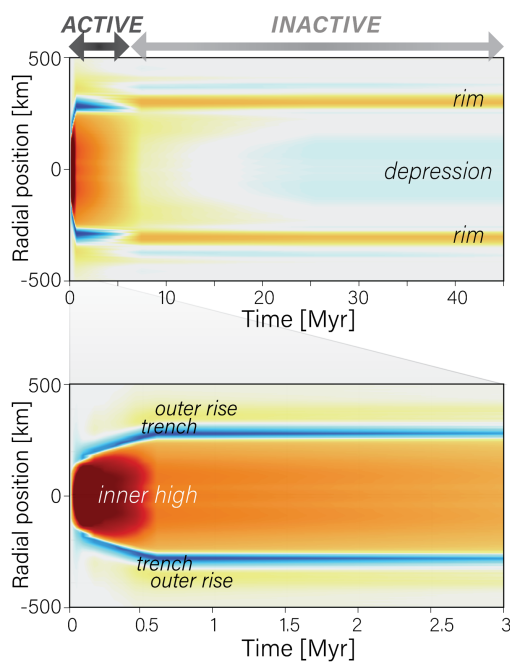

Elevation $[\mathrm{km}]$ c regime III - embedded plume

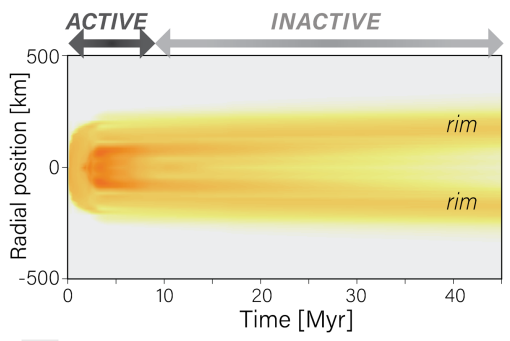

d regime $I V$ - plume underplating

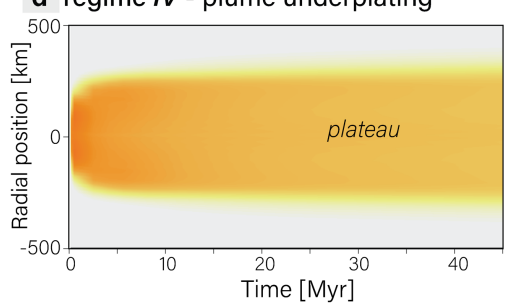

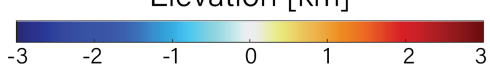

Figure 6 - Temporal evolution of radially-averaged coronae topography for models representing the four identified regimes. $a-b$ ) Reference model MO (lithospheric drips at the plume margins) and model M9 (short-lived radial subduction at the plume margins) show distinct topographic characteristics in their active stage (elevator interior surrounded by a trench and an outer rise) versus inactive stage (interior depression surrounded by an elevated rim); c). Model M2 (transitional regime with embedded plume) also features a rim at final stages and an elevated interior early on but never an outer trench; d) Model M18 (underplated plume) shows an elevated plateau at all times. 


\section{METHODS}

\section{Modelling approach}

A modelling tool designed to investigate the dynamics involved with plume-lithosphere interactions needs to incorporate a thermo-rheologically realistic lithosphere fully coupled to mantle dynamics in three dimensions. We meet this challenge using the staggered grid/particlein-cell viscous-plastic 3D code I3ELVIS ${ }^{53,54}$. This parallel implicit multi-grid code is based on a combination of the finite difference method, applied on a fully staggered Eulerian grid and a marker-in-cell technique 55 . The momentum, continuity, and energy equations are solved on the Eulerian grid, whereas physical properties are transported by Lagrangian markers that move according to the velocity field interpolated from the fixed grid. Non-Newtonian viscous-plastic rheologies are used in the model (Extended Data Table 1), which is also fully thermodynamically coupled and accounts for mineralogical phase changes, adiabatic, radiogenic and frictional internal heating sources. The model takes into account melt extraction and upward transport from the plume, rheological weakening of the lithosphere subjected to melt percolation, crustal growth by magmatic processes, and the basalt to eclogitic phase change to capture the essential geophysical plume-lithosphere interaction processes (see below)

Full details on the method are provided in prior studies ${ }^{55}$ and below. This algorithm has been thoroughly tested, both in two and three dimensions, and used for simulating mantle plume behavior and lithospheric deformation experiments in various previous studies $26,38,41,57$.

\section{Reference model design}

The reference model (MO) set-up is shown in Extended Data Figure 2. A thermal mantle plume (130 km in radius) is placed below a $30 \mathrm{~km}$ thick warm, basaltic crust. The distance between the plume center and the surface is $250 \mathrm{~km}$. The Eulerian domain is equivalent to $2020 \times 2020 \times$ $392 \mathrm{~km}^{3}$ and is resolved with a rectangular grid of $405 \times 405 \times 397$ nodes, containing 256 million randomly distributed markers. The model imposes free-slip boundary conditions on all 
lateral sides, and a lower boundary that is open to mantle flow. The free surface condition on the top boundary is implemented by using a $20 \mathrm{~km}$ thick "sticky" air layer ${ }^{57}$ with a low density (1 $\left.\mathrm{kg} / \mathrm{m}^{3}\right)$ and viscosity $\left(10^{18} \mathrm{~Pa} \cdot \mathrm{s}\right)$. Material parameters used are shown in Extended Table 1. The lithospheric mantle, asthenosphere, and mantle plume all have a dry olivine rheology ${ }^{58}$. The different colors for the lithosphere and asthenosphere are purely for better visualization of potential slabs and drips, whereas the different color for the mantle plume is for visualization of the evolution of initial thermal plume. The initial thermal structure of the lithosphere is calculated according to a prescribed lithospheric age ${ }^{59,60}$, with an additional term depicting an adiabatic thermal gradient $(0.5 \mathrm{~K} / \mathrm{km})$ :

$$
T=T_{0}+\left(T_{1}-T_{0}\right) \operatorname{erf}\left(\frac{y}{2 \sqrt{\kappa t}}\right)+0.0005 \cdot y
$$

where $T_{0}=273 \mathrm{~K}$ and $T_{1}=1573 \mathrm{~K}$ are the surface and asthenospheric mantle temperature, $\kappa=$ $10^{-6} \mathrm{~m}^{2} \cdot \mathrm{s}^{-1}$ is the thermal diffusivity, $t$ is the age of the plate (here set to $40 \mathrm{Myr}$ ) and $y$ is the depth $(\mathrm{m})$. We choose a relatively young lithospheric in the reference model, consistent with recent propositions of a relatively thin and warm (elastic) lithosphere on Venus ${ }^{15,16,17,39}$, as was done in previous 3D numerical modeling of novae and coronae formation ${ }^{26}$. The lower boundary of the lithosphere is defined as the depth of the $1300 \mathrm{~K}$ isotherm, which changes as a function of lithospheric cooling age. The thermal mantle plume has a constant elevated temperature of 1888 $\mathrm{K}$, opposed to the surrounding asthenospheric temperatures of $1580 \mathrm{~K}$ (top of the plume) to 1750 $\mathrm{K}$ (bottom of the plume). Due to this elevated temperature, the upper part of the mantle plume immediately becomes partially molten by decompressional melting (seen in Figs. 4, 5 and Extended Data Fig. 4). The thermal boundary conditions are $737 \mathrm{~K}$ at the top, $1773 \mathrm{~K}$ at the bottom and zero heat flux on all other boundaries. The Venusian surface gravitational acceleration value of $8.87 \mathrm{~m} \cdot \mathrm{s}^{-2}$ is used all models.

\section{Rheology}


Several rock types are considered in both solid and (partially) molten state. The rheological model adopted in our numerical models implies a constant low Newtonian viscosity of $10^{18} \mathrm{~Pa} \cdot \mathrm{s}$ for the partially molten crust and magma extracted from the mantle plume, and a non-Newtonian viscoplastic rheology for the solid crust and mantle based on experimentally determined flow laws (Extended Data Table 1) $)^{58}$. Upper and lower cut-off viscosity limits are set to $10^{24}$ and $10^{18} \mathrm{~Pa} \cdot \mathrm{s}$. Viscous and plastic behavior are implemented via evaluation of the material's effective viscosity. For ductile rheology, contributions from flow laws of both linear diffusion creep as well as powerlaw dislocation creep are taken into account via computation of the inverse average ductile viscosity:

$$
\frac{1}{\eta_{\text {ductile }}}=\frac{1}{\eta_{\text {diffusion }}}+\frac{1}{\eta_{\text {dislocation }}}
$$

in which $\eta_{\text {diffusion }}$ and $\eta_{\text {dislocation }}$ are the effective viscosities for diffusion and dislocation creep, respectively, computed as:

$$
\begin{gathered}
\eta_{\text {diffusion }}=\frac{A_{\mathrm{D}}}{2 \sigma_{\mathrm{cr}}^{n-1}} \exp \left(\frac{E+P V}{R T}\right) \\
\eta_{\text {dislocation }}=\frac{A_{\mathrm{D}}^{1 / n}}{2} \exp \left(\frac{E+P V}{n R T}\right) \dot{\varepsilon}_{I I}{ }^{\frac{1}{n}-1}
\end{gathered}
$$

where $P$ is pressure, $T$ is temperature (in K), $R$ is the gas constant (8.314), $\dot{\varepsilon}_{I I}=\sqrt{\frac{1}{2} \dot{\varepsilon}_{i j} \dot{\varepsilon}_{i j}}$ is the second invariant of the strain rate tensor (the overdot indicates differentiation with respect to time and the repeated indices $i, j$ here and elsewhere imply summation), $\sigma_{\mathrm{cr}}$ is the diffusiondislocation transition stress ${ }^{59}$ and $A_{\mathrm{D}}, E, V$, and $n$ correspond to the experimentally determined material constant, the activation energy, the activation volume and the stress exponent, respectively.

For the brittle (plastic) rheology of the plates, strain and melt weakening are assumed ${ }^{55,61}$, induced by percolation of magma through deforming rocks. We use a modified Drucker-Prager yield strength criterion defining the visco-plastic transition:

$$
\eta_{\text {viscous }} \leq \frac{\sigma_{I I}}{2 \dot{\varepsilon}_{I I}} \text { with } \sigma_{I I}=C+\phi P \lambda_{\text {melt }}^{\text {eff }}
$$




$$
\begin{array}{cc}
\phi=\phi_{0}\left(1-\gamma / \gamma_{0}\right) & \text { for } \gamma \leq \gamma_{0} \\
\phi=0 & \text { for } \gamma>\gamma_{0} \\
\gamma=\int \sqrt{\frac{1}{2}\left(\dot{\varepsilon}_{i j(\text { plastic })}\right)^{2} d t}
\end{array}
$$

where $P$ is the total rock pressure, $\phi$ is the internal friction coefficient with $\phi_{0}$ as the initial friction coefficient, taken to be $\mathbf{0 . 2}$ for the weak Venusian rheology (following approaches of Gerya et al. $\left.{ }^{26,55}\right), \gamma \geq 0$ the time-integrated plastic strain that is integrated as long as plastic deformation is active ( $\gamma_{0}=0.5$ is the upper strain limit for fracture-related weakening), $C$ is the compressive rock strength at $P=0, t$ is time in seconds, $\dot{\varepsilon}_{i j \text { (plastic) }}$ is the plastic strain rate tensor, and $\lambda_{\text {melt }}^{\text {eff }}$ is the long-term melt-induced weakening factor ${ }^{56}$ defined by:

$$
\begin{array}{ll}
\lambda_{\text {melt }}^{\text {eff }}=\lambda_{\text {melt }, 0} & \text { for } f_{\text {melt }} \geq f_{\text {melt }, 0} \\
\lambda_{\text {melt }}^{\text {eff }}=1-\left(1-\lambda_{\text {melt }, 0}\right) \frac{f_{\text {melt }}}{f_{\text {melt }, 0}} & \text { for } f_{\text {melt }}<f_{\text {melt }, 0}
\end{array}
$$

where $\lambda_{\text {melt, } 0}$ is the standard value for melt-induced weakening, $f_{\text {melt }}$ is the local melt flux, and $f_{\text {melt, } 0}$ is the melt flux needed to be reached for melt-induced weakening. Such softening behavior is commonly accepted for fluid- and melt-bearing lithosphere ${ }^{54}$ and implies that mantlederived melts are able to weaken the rock significantly. Melt-induced weakening $\left(\lambda_{\text {melt }}^{\text {eff }}<1\right)$ is applied locally on lithospheric rock markers vertically above areas of melt extraction (averaged for each vertical column of grid cells) at a given timestep, whereas for all other rocks no magmatic weakening is assumed $\left(\lambda_{\text {melt }}^{\text {eff }}=1\right)$. Moreover, the effective melt-induced weakening factor $\lambda_{\text {melt }}^{\text {eff }}$ is assumed to change locally according to the local melt flux $f_{\text {melt }}$ from one (when $f_{\text {melt }}=0$ ) to the standard value of $\lambda_{\text {melt, } 0}=0.01$ (when $f_{\text {melt }} \geq f_{\text {melt, } 0}$ ). The local melt flux reflects the local rate of crustal growth in the model, and the maximal local melt flux value $\left(f_{\text {melt, } 0}\right)$ may affect the magnitude of magmatic weakening. The value of the maximum local melt flux is set to $10^{-10} \mathrm{~m} \cdot \mathrm{s}^{-1}$ $(3.16 \mathrm{~mm} / \mathrm{yr})$ in the reference model. Values for the long-term lithospheric weakening factor $\lambda_{\text {melt,0 }}$ were quantified on the basis of 2D numerical experiments ${ }^{54}$, and determined to be of the order of $10^{-3}$ to $10^{-2}$. Recent numerical studies on the geodynamics of Southwestern North America found that such high melt/fluid-induced lithospheric weakening is necessary to 
reproduce the observed deformation style of the region, a suggestive validation of the concept of melt-induced weakening ${ }^{61}$.

\section{Partial melting and melt extraction}

Partial melting of the mantle plume, melt extraction and melt percolation towards the bottom of the crust are implemented in a simplified manner ${ }^{55,60}$. For the crust, the pressure- and temperature-dependent volumetric melt fraction $M_{0}$ is calculated using a simple linear batch melting model ${ }^{62}$ in which the amount of (partial) melting increases linearly between $T_{\text {solidus }}$ and $T_{\text {liquidus: }}$

$$
\begin{array}{ll}
M_{0}=0 & \text { when } T<T_{\text {solidus }} \\
M_{0}=\left(T-T_{\text {solidus }}\right) /\left(T_{\text {liquidus }}-T_{\text {solidus }}\right) & \text { when } T_{\text {liquidus }}<T<T_{\text {solidus }} \\
M_{0}=1 & \text { when } T>T_{\text {liquidus }},
\end{array}
$$

where $T_{\text {solidus }}=1327+0.091 \cdot P$ and $T_{\text {liquidus }}=1432+0.105 \cdot P$ are the solidus and liquidus temperatures (in $\mathrm{K}$ ) of the crust at a given pressure $\mathrm{P}$, respectively. For the mantle, the non-linear parametrized batch melting model of Katz et al. ${ }^{62}$ is used to calculate $M_{0}$. In all lithologies, Lagrangian markers track the amount of extracted melt during the evolution of each experiment. The total amount of melt, $M$, for every marker takes into account the amount of previously extracted melt and is calculated as:

$$
M=M_{0}-\sum_{m} M_{\mathrm{ext}}
$$

where $\sum_{m} M_{\text {ext }}$ is the total melt fraction extracted during the previous $m$ melt extraction episodes. At time step zero all lithologies are assumed to be melt-depleted $\left(\sum_{m} M_{\text {ext }}=M_{0}\right)$. Rocks are considered non-molten (refractory) when the extracted melt fraction is larger or equal than the standard one $\left(\sum_{m} M_{\text {ext }}=M_{0}\right)$. To simulate melt extraction, an extraction threshold $M_{\max }=4 \mathrm{wt} . \%$ is defined. If the total amount of melt $M$ surpasses this threshold $\left(M>M_{\max }\right)$, all melt except a non-extractable $M_{\min }=2 \mathrm{wt} . \%$ is extracted: $\sum_{m+1} M_{\text {ext }}=\sum_{m} M_{\text {ext }}+M-M_{\min }$. 
Melt percolation is assumed to be faster than the deformation of non-molten mantle ${ }^{63}$. Based on this assumption, the extracted melt $M_{\text {ext }}$ is instantaneously removed from its source region, moved upwards vertically, and is added to the bottom of the crust as intrusive plutons or to the surface as volcanic rocks according to a predefined plutonic-to-volcanic rock ratio (80:20\%).

The effective density of the mafic magma and molten crust is computed as ${ }^{60}$ :

$$
\rho_{\text {eff }}=\rho_{\text {solid }}\left(1-M+M \frac{\rho_{0, \text { molten }}}{\rho_{0, \text { solid }}}\right)
$$

where $\rho_{0, \text { solid }}=3000 \mathrm{~kg} / \mathrm{m}^{3}$ and $\rho_{0, \text { molten }}=2800 \mathrm{~kg} / \mathrm{m}^{3}$ are the standard densities of solid and molten crust, respectively, and $\rho_{\text {solid }}$ is the density of solid crust at a given $P$ and $T$, which is calculated as:

$$
\rho_{\text {solid }}=\rho_{0, \text { solid }}[1-\alpha(T-298)] \cdot[1+\beta(P-0.1)]
$$

with thermal expansion $\alpha=3 \cdot 10^{-5} \mathrm{~K}^{-1}$ and compressibility $\beta=10^{-5} \mathrm{MPa}^{-1}$ of the crust. The effect of latent heating due to equilibrium crystallization of molten rocks is implicit in the heat conversation equation by increasing the effective heat capacity $\left(C_{P, \text { eff }}\right)$ and the thermal expansion $\left(\alpha_{\mathrm{eff}}\right)$ of the partially crystallized/molten rocks $(0<M<1)$, calculated as:

$$
\begin{gathered}
C_{P, \text { eff }}=C_{P}+Q_{\mathrm{L}}\left(\frac{\partial M}{\partial T}\right)_{P=\mathrm{cst}} \\
\propto_{\mathrm{eff}}=\propto+\rho \frac{Q_{\mathrm{L}}}{T}\left(\frac{\partial M}{\partial P}\right)_{T=\mathrm{cst}}
\end{gathered}
$$

where $C_{P}=1000 \mathrm{~J} / \mathrm{kg}$ is the heat capacity of the solid crust and $Q_{\mathrm{L}}=380 \mathrm{~kJ} / \mathrm{kg}$ is the latent heat of crystallization of the crust $^{59}$.

\section{Phase changes}

Eclogitization of dripping or subducted crust is implemented as a linear density increase with pressure from $0 \%$ to $16 \%$ in the pressure-temperature region of garnet-in and plagioclase-out phase transitions in basalt (Extended Data Fig. 3$)^{64}$. 
Numerical implementations of slab dehydration and mantle hydration used in former numerical studies on 3D plume-lithosphere explorations ${ }^{38,54}$ are deactivated in the code, so that our model represents a dry planetary interior appropriate for Venus.

\section{Heat flux calculations}

Vertical heat flows are calculated for each model just beneath the surface at a given depth. We choose a depth slightly below the surface $\left(y_{\text {surf }}=1 \mathrm{~km}\right)$ such to not be affected by possibly high thermal conductivity values for the sticky air. To do so, heat flow $q$ (in $\mathrm{W} / \mathrm{m}^{2}$ ) is calculated at the center of the neighboring cell (above and below this depth) using:

$$
q_{\mathrm{i}}=\kappa_{i} \frac{d T_{i}}{d y}
$$

with averaged thermal conductivity $\kappa_{i}$ for cell $i$ (equations for thermal conductivity are given in

Extended Data Table 1), and the vertical thermal gradient $\frac{d T_{i}}{d y}$. The sign conventions ensure positive values of heat flow ${ }^{59}$. The heat flow is then calculated as:

$$
q_{\text {surf }}=q_{1}+\frac{d q}{d y} \cdot\left(y_{\text {surf }}-y_{1}\right)
$$

Heat flow values are averaged over the corona interior to estimate an effective heat flux of the corona region.

\section{Forces related to mantle plumes and lithosphere dynamics}

Density anomalies drive plume ascent and control the forces applied at the base of the lithosphere ${ }^{65}$. A simple approach to estimate the buoyancy force $F_{\mathrm{B}}$ associated with the mantle plume is to consider the density anomaly $\Delta \rho$, consisting of a thermal component due to thermal expansion of the plume material (with initial density $\rho_{\text {plume }}$ ) induced by a temperature difference $\Delta T$, and a chemical component due to the difference in composition $\Delta \rho_{\text {chem }}$ :

$$
\Delta \rho=\rho_{\text {plume }} \alpha \Delta T+\Delta \rho_{\text {chem }}
$$


where $\alpha$ is the thermal expansion of the plume material. The buoyancy force exerted by a spherical plume with radius $R$ is defined as:

$$
F_{\mathrm{B}}=\frac{4}{3} \pi R^{3} \Delta \rho g
$$

with gravitational acceleration $g$. In non-Newtonian fluids, a very small variation in buoyancy force results in a strong variation in the plume ascent behavior ${ }^{65,66,67}$.

There is no forthright way of establishing the strength of a planet's lithosphere. One way is to follow the consideration that in the upper, colder part of the lithosphere, the deformation mechanism is dominated by friction plasticity ${ }^{38,42}$. Taking the maximum lithostatic pressure to be $\rho g H_{\mathrm{L}}$, the maximum lithospheric frictional strength $F_{\mathrm{L}}$ can be defined as:

$$
F_{\mathrm{L}}=C+\varphi_{\mathrm{eff}} \rho g H_{\mathrm{L}}
$$

in which $C$ is the compressive strength of the lithospheric material, $\rho$ is the density of the lithosphere, $H_{\mathrm{L}}$ is the thickness of the lithosphere and $\varphi_{\text {eff }}$ is the effective friction coefficient above the plume (see rheology section), which according to the brittle viscosity equation may be lowered locally by the presence of melts in the rock.

Using numerical models of plume-lithosphere interactions, it has been shown that the ability of a plume to penetrate though a lithosphere is determined by a non-dimensional ratio between the plume buoyancy stress and lithospheric frictional strength, the plume buoyancy ratio $B r^{38,41}$.

$$
B r=\frac{R g \rho_{\text {plume }} \alpha \Delta T}{C+\varphi_{\text {eff }} \rho g H_{L}}
$$

It is important to note that the numerical technique used here differs significantly to those used in previous modelling efforts of plume-lithosphere interactions on Earth ${ }^{38,41}$ and $\operatorname{Venus}^{26}$, especially in terms of the applied tectono-magmatic model. Prior studies did not take into account any melt-induced weakening approach ${ }^{26,38}$ or imposed a globally weak lithosphere instead of the locally applied (both in space and time) weakening as is done here. These discrepancies would allow for different behaviors of plume-lithosphere interactions and different 
definitions of $\varphi_{\text {eff }}$ in the Buoyancy ratio equation (see above). Moreover, in the previous 3D study of small-scale plume-lithosphere interactions on Venus ${ }^{26}$, melt could only move mechanically through the lithosphere. For these reasons, and the fact that model set-ups, geometries as well as resolutions differ between the studies, one should take caution in directly comparing the results of previous studies ${ }^{26,38,41}$ with ours.

\section{Limitations of the numerical models and speed of model evolution}

Several limitations of our employed method must be mentioned. First, our employed tectonomagmatic formulation does not precisely reflect the physics involved in various tectonomagmatic processes, such as partial melting of the mantle plume, melt extraction and melt percolation towards the bottom of the crust. By assuming instantaneous melt percolation towards the crust, no flow field divergence is created in response to melt accretion to the bottom of the magma region. This assumption results in an overestimation of the speed at which the plume penetrates through the lithosphere. Similarly, the adopted melt-induced weakening does not precisely reflect the physics involved in the various weakening/healing processes, such as melt percolation and grain damage or growth. Further theoretical development and numerical implementation of a more sophisticated and realistic lithospheric weakening/healing model is needed. Moreover, the large-scale visco-plastic rheological model of the lithosphere is simplified and does not account for rock elasticity (promoting the development of more tectonic and fractural features) and damage processes, nor does it account for (partial) healing of deactivated fractures $^{53}$. The largely viscous rheologic behavior of lithosphere and mantle materials in the models (mainly due to magmatic weakening) also preludes the inferences of clear tectonic structures at the surface and promotes the stability of full-annulus circular slabs in the ephemeral subduction models.

The Eulerian grid used in most of the experiments is discretized in cells that represent a volume of $5 \times 5 \times 2 \mathrm{~km}^{3}$. Even though the many Lagrangian markers better resolve the transitions in rock types and physical properties than this resolution, the grid size precludes the analysis of small-scale localized shear zones. Higher resolution models would be needed to assess 
more detailed localized tectonic features displayed by individual coronae on Venus. Finally, assumptions that have been made with the initial model set-up also promote a relatively rapid evolution of the models. First off, our set-up places a mantle plume right beneath the Venusian lithosphere (Extended Data Fig. 1), resulting in near-instantaneous crustal uplift. Secondly, the mantle potential temperature was not investigated in this study. Higher mantle potential temperatures lead to a compositionally more buoyant lithosphere ${ }^{68}$, yet also to a relatively less buoyant mantle plume, which might slow down model evolution. Finally, plume activity at the surface could be prolonged by the constant supply to the coronae by heat and magma coming from multiple plumes ${ }^{69}$ or an active plume-tail ${ }^{70}$.

\section{Comparison with natural data}

Numerical results and visualizations thereof can be compared with available observational data of the Venusian surface. While a reasonable amount of topographic maps and radar images is supplied by previous published work ${ }^{25,71}$ original data sets from planetary missions, particularly the NASA Magellan mission, provide the full scope of Venusian surface observations. Data acquired by the Magellan mission has been made accessible on the PDS Geosciences Node Venus Orbital Data Explorer (http://ode.rsl.wustl.edu/venus/index.aspx), and datasets vary in file format and purpose. As the brightness of radar images depend on roughness, topography and electric properties, SAR image mosaics are useful for structural analysis of the Venusian surface. Radar altimetry measurements are collected as Global Topography Data Record (GTDR), from which global topographic maps have been produced ${ }^{47}$. The Magellan topography data set has a horizontal resolution of $10-25 \mathrm{~km}$, and a nominal vertical resolution of $80 \mathrm{~m}^{72}$. The open-source software package Generic Mapping Tools (GMT) ${ }^{73}$ was used for visualization of the freely available NASA gridded topography data of Venus ${ }^{47}$.

The most complete dataset of corona locations openly available at present is the USGS coronae nomenclature database ${ }^{45}$. While there may have been over 500 coronae features counted on the Venusian surface, 347 corona structures had been requested an official name for 
and are hence used in previous scientific studies, which are listed in this database. In our global coronae analysis, we focus on coronae that are best resolved by the observable data and with comparable dimensions to those in our numerical experiments, and therefore analyze only coronae with a diameter of $>300 \mathrm{~km}$, encompassing $\sim 40 \%$ of the database. In addition, we analyzed several coronae with smaller dimensions that are situated in formerly identified "hot spots $^{16,19,46}$.

\section{Data availability}

The numerical data that supports the findings of this study can be requested from the corresponding author. A KML file based on the coronae classification in this paper is available on Gülcher et al. (2020) ${ }^{51}$, and can be used in Google Earth or Google Venus. The source data of the USGS coronae nomenclature is publicly available at https://planetarynames.wr.usgs.gov/SearchResults?target=VENUS\&featureType=Corona, coronae $^{43}$, and the global topography at https://topex.ucsd.edu/pub/sandwell/google/venus ${ }^{45}$.

\section{Code availability}

The numerical code is available upon reasonable request. Requests can be made to T.V. Gerya.

\section{REFERENCES}

53. Gerya, T. V., \& Yuen, D. A. Robust characteristics method for modelling multiphase viscoelasto-plastic thermo-mechanical problems. Physics of the Earth and Planetary Interiors $163,83-105$ (2007)

54. Gerya, T. V., Stern, R. J., Baes, M., Sobolev, S. V., \& Whattam, S. A. Plate tectonics on the Earth triggered by plume-induced subduction initiation. Nature 527, 221-225 (2015)

55. Gerya, T. V. Introduction to numerical geodynamic modelling (Cambridge University Press, Cambridge, 2010) 
56. Koptev, A., Calais, E., Burov, E., Leroy, S., \& Gerya, T. Dual continental rift systems generated by plume-lithosphere interaction. Nature Geoscience 8, 388-392 (2015)

57. Schmeling, $\mathrm{H}$. et al. A benchmark comparison of spontaneous subduction models-Towards a free surface. Physics of the Earth and Planetary Interiors 171, 198-223 (2008)

58. Ranalli, G. Rheology of the Earth, 2nd edition (Springer, 1995)

59. Turcotte, D. L. and Schubert, G. Geodynamics, $2^{\text {nd }}$ edition (Cambridge University Press, 2002)

60. Gerya, T. V. Three-dimensional thermomechanical modeling of oceanic spreading initiation and evolution. Physics of the Earth and Planetary Interiors 214, 35-52 (2013)

61. Bahadori, A. and Holt, W.E. Geodynamic evolution of southwestern North America since the Late Eocene, Nature Communications, 10, 5213 (2019)

62. Katz, R. F., Spiegelman, M., \& Langmuir, C. H. A new parameterization of hydrous mantle melting. Geochemistry, Geophysics, Geosystems 4, 1073 (2003)

63. Connolly, J. A. D., Schmidt, M. W., Solferino, G., \& Bagdassarov, N. Permeability of asthenospheric mantle and melt extraction rates at mid-ocean ridges. Nature 462, 209-212 (2009)

64. Ito, K. and Kennedy, G. An experimental study of the basalt-garnet granulite-eclogite transition. In The structure and physical properties of the Earth's crust, J.G. Heacock (ed.), 301-314 (1971)

65. d'Acremont, E., Leroy, S., \& Burov, E. B. Numerical modelling of a mantle plume: The plume head-lithosphere interaction in the formation of an oceanic large igneous province. Earth and Planetary Science Letters 206, 379-396 (2003)

66. Weinberg, R. F. and Podladchikov, Y. Diapiric ascent of magmas through power law crust and mantle. Journal of Geophysical Research, 99, 9543-9559 (1994)

67. Burov, E., \& Cloetingh, S. Plume-like upper mantle instabilities drive subduction initiation. Geophysical Research Letters 37, L03309 (2010)

68. Korenaga, J. Initiation and Evolution of Plate Tectonics on Earth: Theories and Observations. Annual Review of Earth and Planetary Sciences 41, 117-151 (2013) 
69. Harris, L. B. and Bedard, J. (2013). Crustal evolution and deformation in a non-plate tectonic Archaean Earth: comparisons with Venus. In: Dilek Y., Furnes, H. (eds.) Evolution of Archean Crust and Early Life, Modern Approaches in Soled Earth Sciences, ch 9 (Springer, 2013)

70. Jellinek, A. M. The influence of interior mantle temperature on the structure of plumes: Heads for Venus, Tails for the Earth. Geophysical Research Letters 29, 1532 (2002)

71. Ivanov, M. A., \& Head, J. W. Global geological map of Venus. Planetary and Space Science, 59, 1559-1600 (2011)

72. Pettengill, G. H., Ford, P. G., \& Wilt, R. J. Venus surface radiothermal emission as observed by Magellan. Journal of Geophysical Research 97, 13091 (1992)

73. Wessel, P. and Smith, W. Generic Mapping Tools: Improved version released. EOS Trans. AGU 94, 409-410 (2013)

74. D'Incecco, P., Mueller, N., Helbert, J. and D'Amore, M. Idunn Mons on Venus: Location and extent of recently active lava flows. Planetary and Space Science 136, 25-33 (2016) 


\section{EXTENDED DATA}

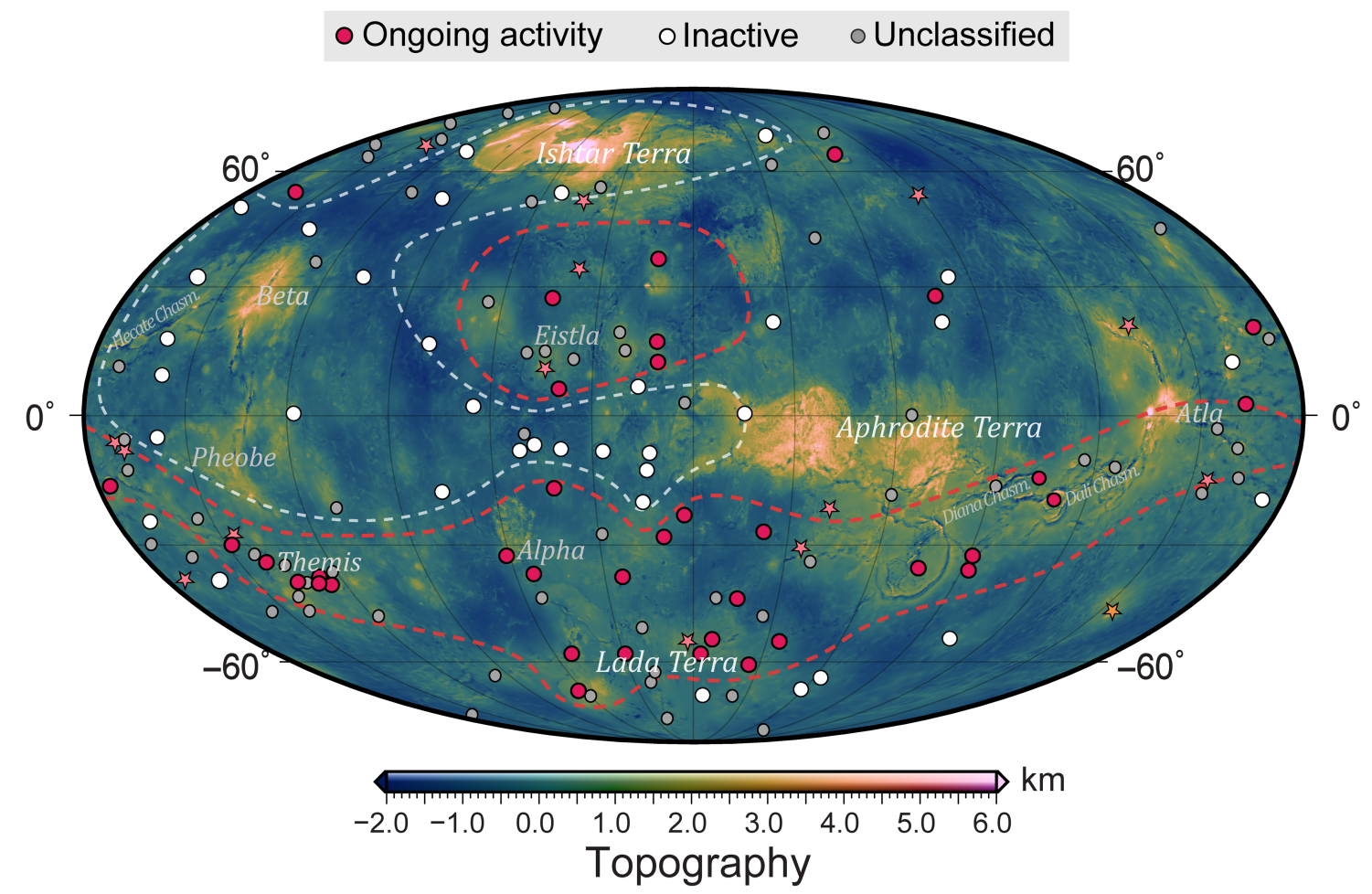

Extended Data Figure 1 - Global distribution of coronae (diameter > $300 \mathrm{~km}$ ) identified as inactive (white circles), showing ongoing activity (red circles) or unclassified (grey circles). The global topography ${ }^{47}$ is relative to $6051.877 \mathrm{~km}$ and is plotted on a Mollweide projection centered at $60^{\circ} \mathrm{E}$ longitude. Nomenclature of key areas and chasmata are shown in light text. Pink stars relate to the locations of identified raised novae structures ${ }^{49}$ proposed to be sites of ongoing plume activity ${ }^{26}$. The orange star correspond to Idunn Mons, an identified location of recently active lava flows ${ }^{16,74}$. All analyzed coronae are recorded in Supplementary Table 1. A KML file containing the location of each of the coronae is available on Gülcher et al. (2020) ${ }^{51}$. The dashed lines contour our proposed areas of focused plume activity (red) or inactivity (white). 


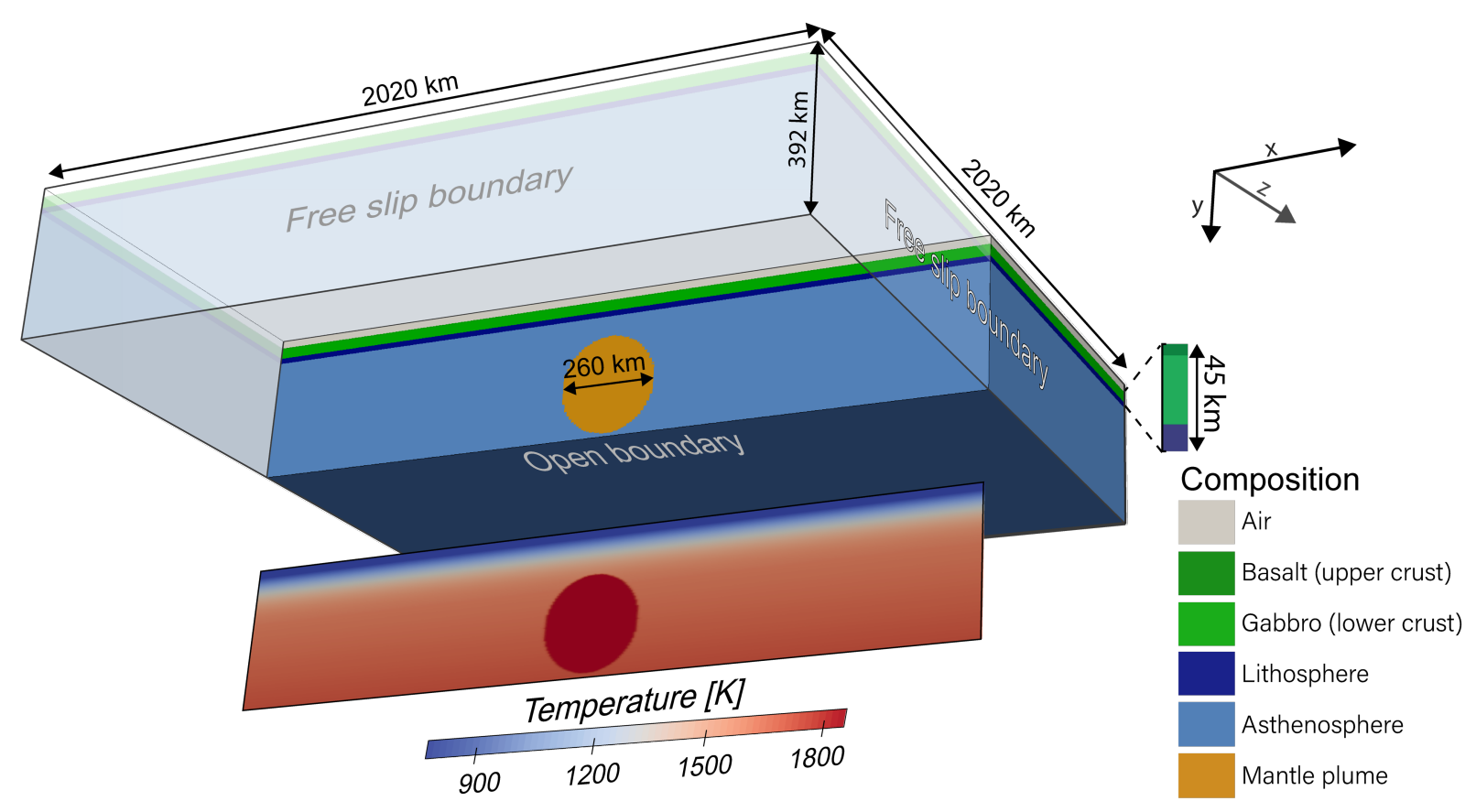

Extended Data Figure.2 - Numerical model design and boundary conditions. Details can be found in Methods description. A 2D cross-section through the center of the model shows initial composition configuration (upper cross-section) and initial temperature distribution (lower crosssection). The vertical model boundaries in the $x$ and $z$ direction are symmetrical. The color code for different materials is shown at the bottom of the figure. 
a

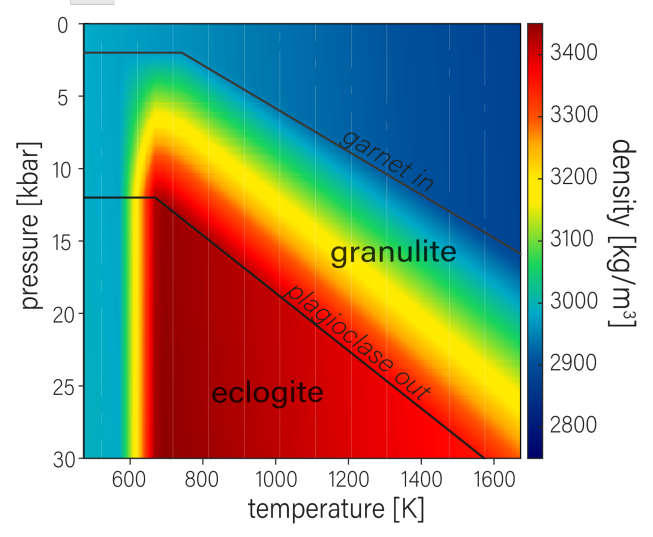

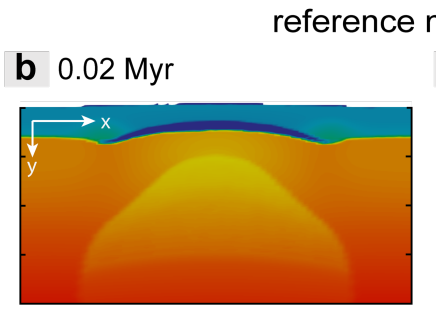

C $0.04 \mathrm{Myr}$

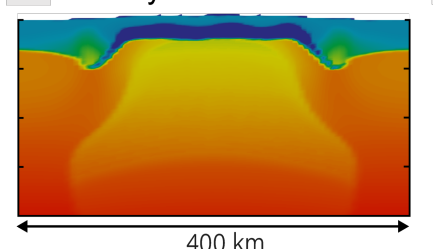

$400 \mathrm{~km}$ d $0.06 \mathrm{Myr}$

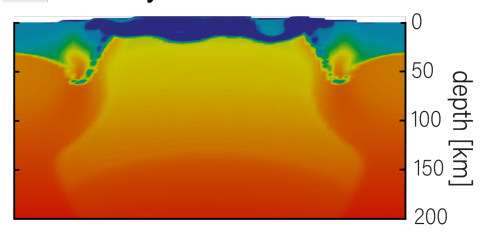

e $0.09 \mathrm{Myr}$

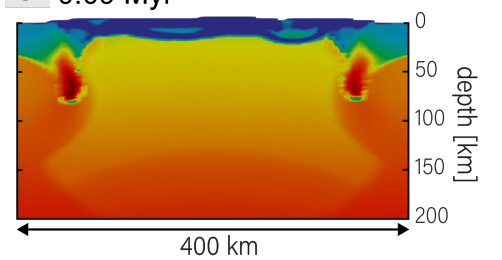

Extended Data Figure 3 - Density increase of crustal material due to the basalt to eclogite phase change. a) P-T region of the density increase due to the eclogitic phase change ${ }^{64}$, as implemented in our numerical code (see Methods) (b-d) Close-up on the short-term evolution of the reference model MO (Fig. 1, main text). The density is shown in the cross-sections, and as the mantle plume pierces through the lithosphere, the lithosphere at the plume margin is pushed downwards and its density subsequently increases as it undergoes the basalt to eclogite phase change. 


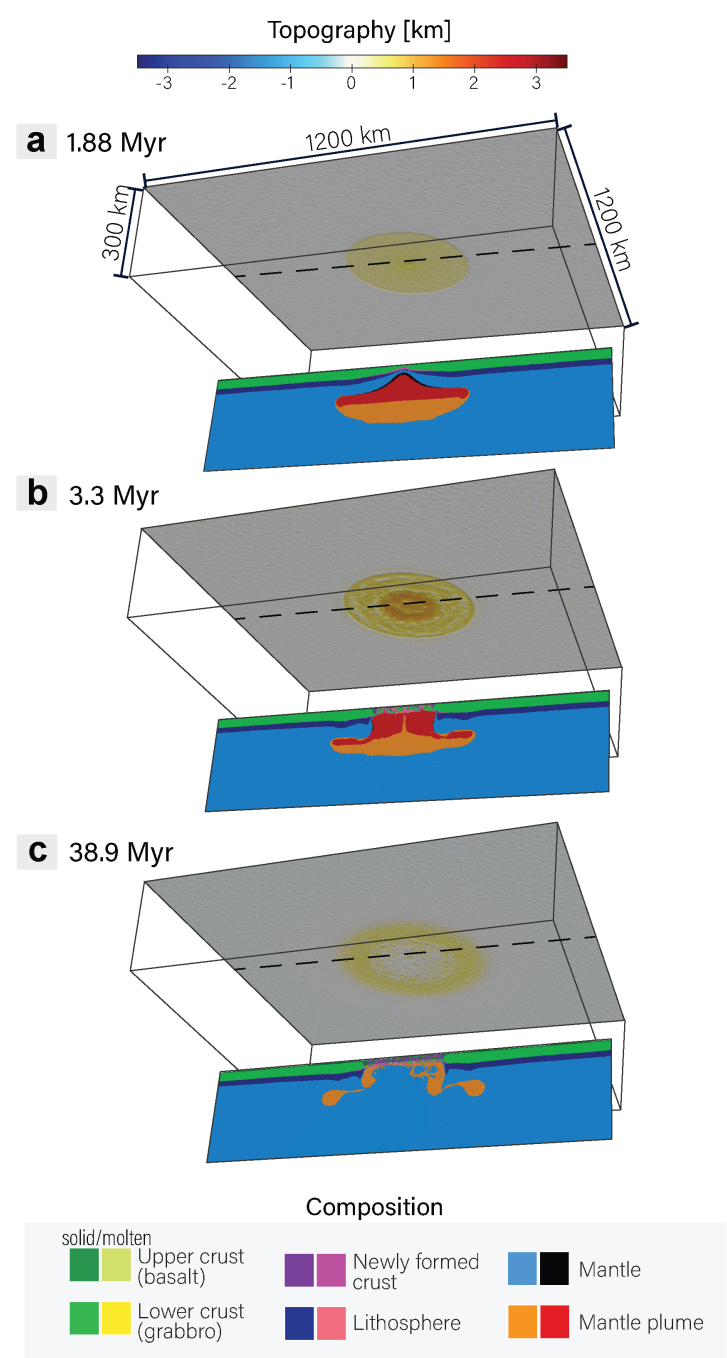

Extended Data Figure 4 - Evolution of a corona model in the transitional regime featuring an embedded plume (Model M2). Model M2 has a colder initial mantle plume than the reference model, and thus a lower plume buoyancy (see Extended Data Table 2 for details of the models). (a) the plume rises up to the surface, resulting in crustal uplift (at $1.88 \mathrm{Myr}$ ); (b) the plume partially penetrates through the lithosphere but becomes embedded (at $3.24 \mathrm{Myr}$ ); (c) the plume cools down and molten material recrystallizes, and the corona interior sinks to leave behind a raised rim (at 38.9 Myr). 
a model $M 9$
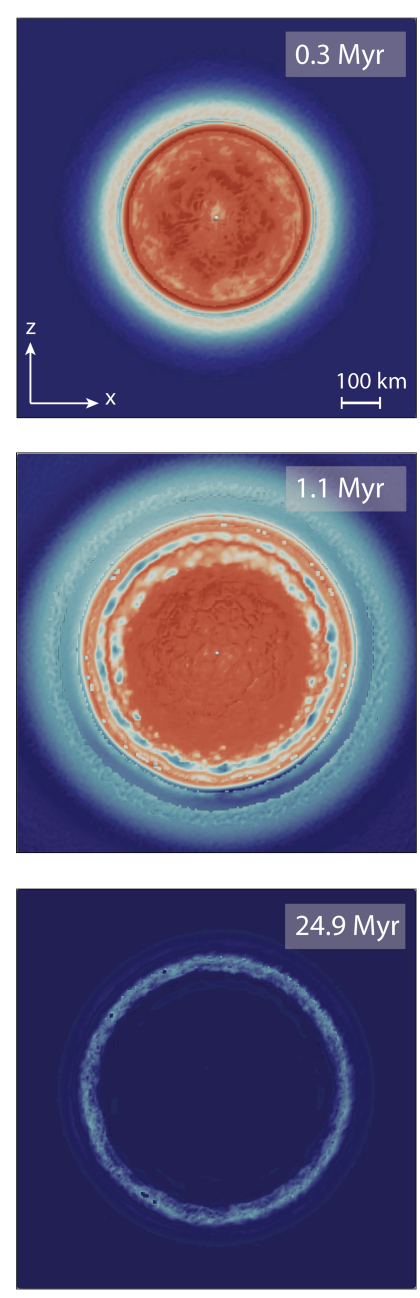

b model $\boldsymbol{M} 2$
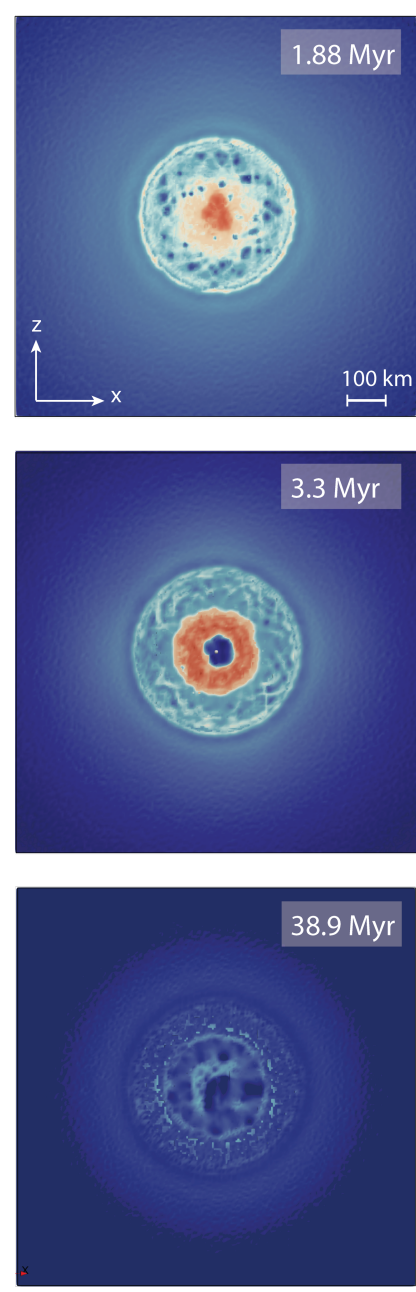

$\dot{\varepsilon}_{\text {II }}\left[\mathrm{s}^{-1}\right]$
C model $M 17$
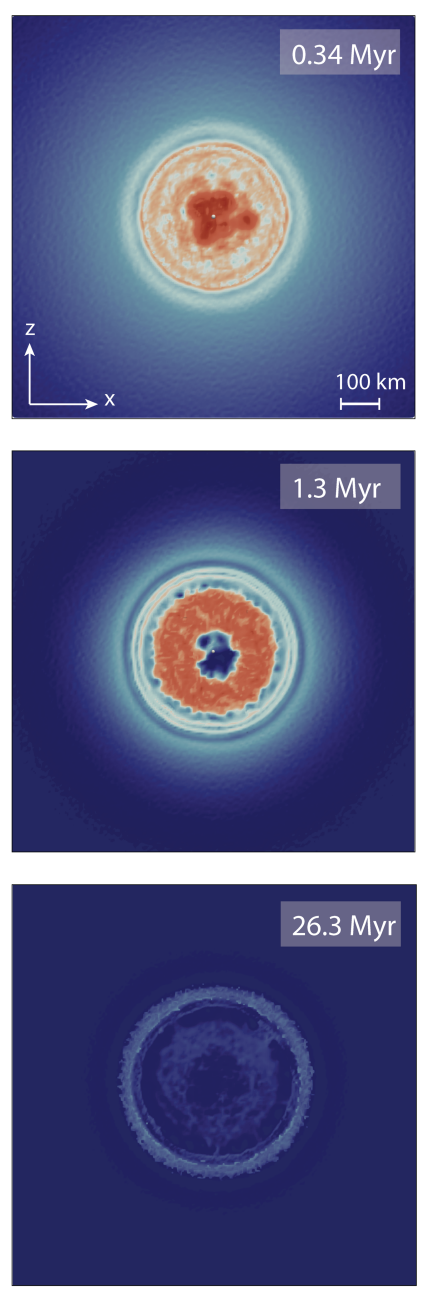

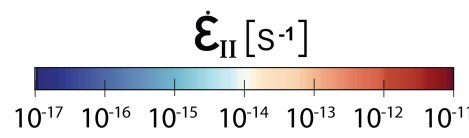

Extended Data Figure 5 - Surface strain rate for three evolutionary stages of models M9 (left), M2 (middle) and M17 (right). See Extended Data Table 2 for details of the models. (a) model M9 (reference model for "ephemeral subduction" regime): the penetrating plume fully penetrates the lithosphere and crust resulting in a high strain rate, viscous corona interior in which deformation structures cannot be distinguished. Concentric deformation features at the corona margin can be recognized throughout the model evolution. The times of the snapshots correspond to those shown in Figs. 5a-c. (b) model M2 (reference model for "embedded plume" regime): more deformation structures can be recognized due to less melt at the surface. In addition to concentric 
Accepted manuscript: Gülcher et al. (2020), Nature Geoscience: https://doi.org/10.1038/s41561-020-0606-1

features, stellate deformation features trace the surface in the first two stages. The timing of the snapshots corresponds to those shown in Extended Data Fig. 4. (c) model M17 (also categorized as "embedded plume" regime): many concentric and few radial deformation features can be observed at the surface. Important to note is that our model resolution and simplifications do not allow for a more detailed interpretation of tectonic structures at the surface and comparison thereof with observables (see Methods). 
a Lithospheric dripping

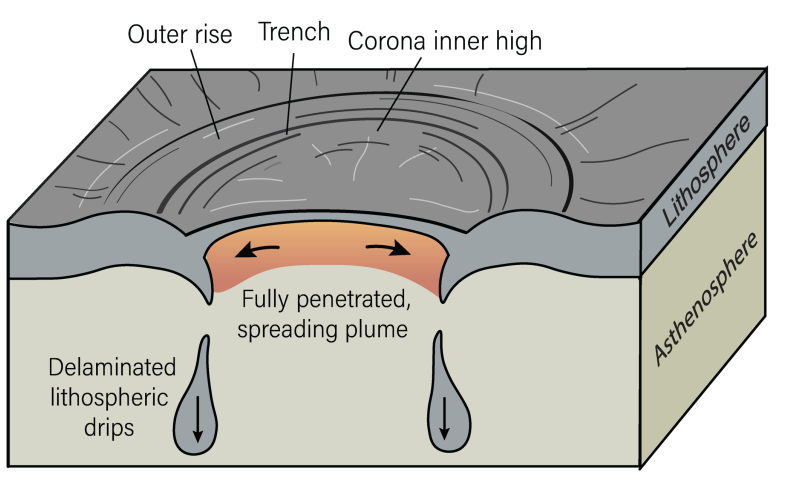

C Embedded plume

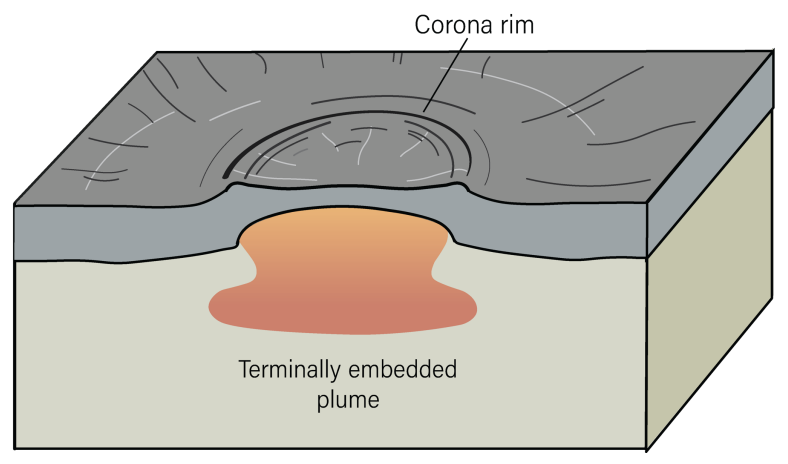

b Ephemeral subduction

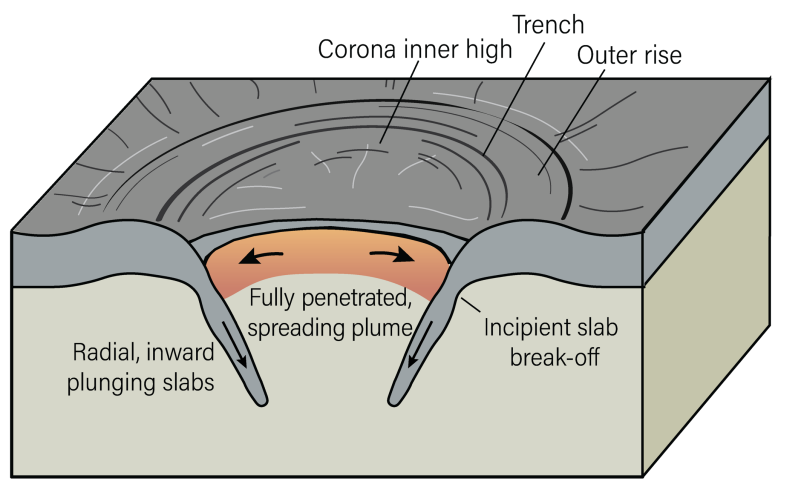

d Plume underplating

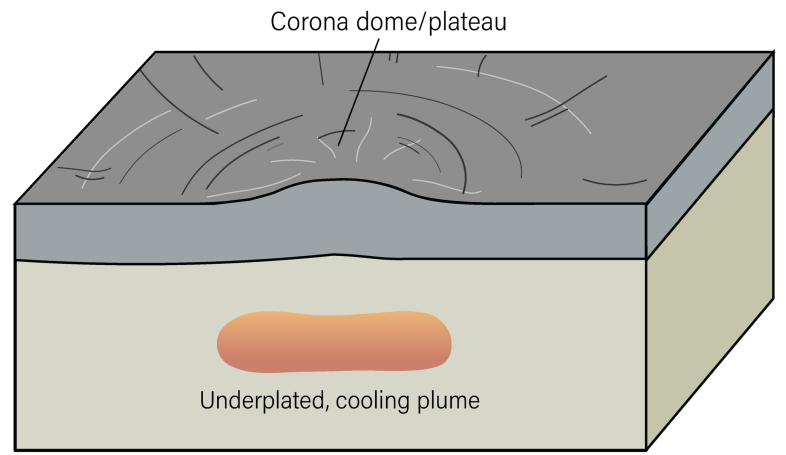

Extended Data Figure 6 - Sketches of the four geodynamic regimes identified in numerical models, during the active stage: (a) Lithospheric dripping - in which mantle plume penetration into the lithosphere is followed by delamination of lithospheric drips at the plume margins. (b) Ephemeral subduction; in which a short-lived radial subduction zones follows plume impingement. The downgoing slabs eventually break off. (c) Embedded plume (transitional regime), in which the plume is able to penetrate partially through the lithosphere but is terminally embedded beneath the crust. (d) Plume underplating, in which the mantle plume is not able to pierce through the lithosphere but instead spreads outward beneath it. 


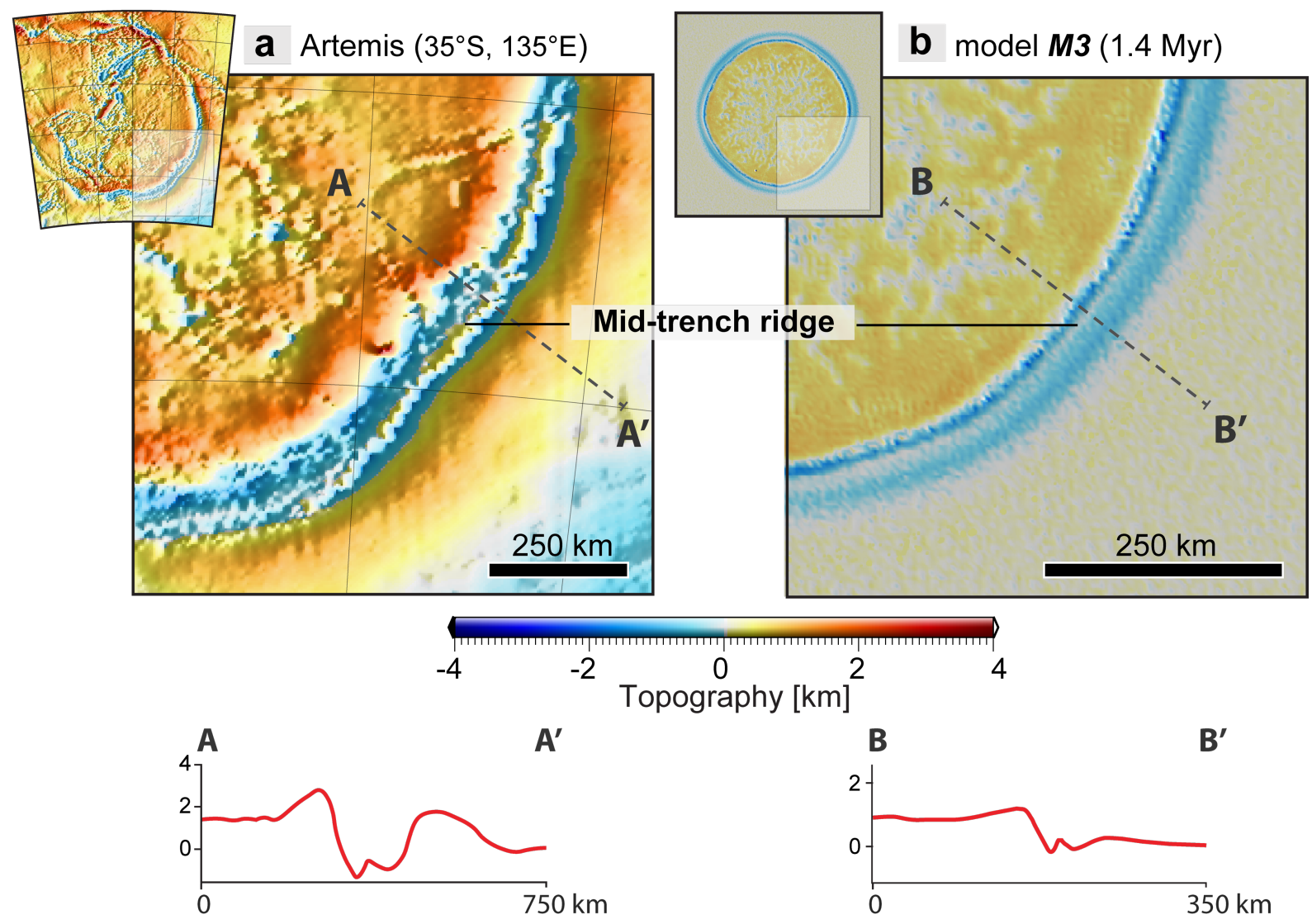

Extended Data Figure 7 - Comparison between topographic signatures displayed by the Artemis corona (left) and the simulated coronae in model M3 at time t=1.4 Myr (right). Color code in both images has the same scale. The Artemis topographic profile is plotted with $\mathrm{GMT}^{73}$ based on the global topography data ${ }^{47}$. Both models show a small but clear ridge within the coronaencircling trench, characteristics in numerical models for the period shortly following lithospheric break-off/delamination and trench uplift. It is notable that the shoulders on the southeast of the figures are markedly different. This could possibly be ascribed due to the fact that the modelled case features lithospheric dripping and not subduction (as is proposed for Artemis $30,31,32,43,45$ ). Models with greater scaled crustal thicknesses $\left(H_{\text {crust }} / H_{\text {lith }}\right)$ have shown to produce higheramplitude trenches and outer rises (see text). 


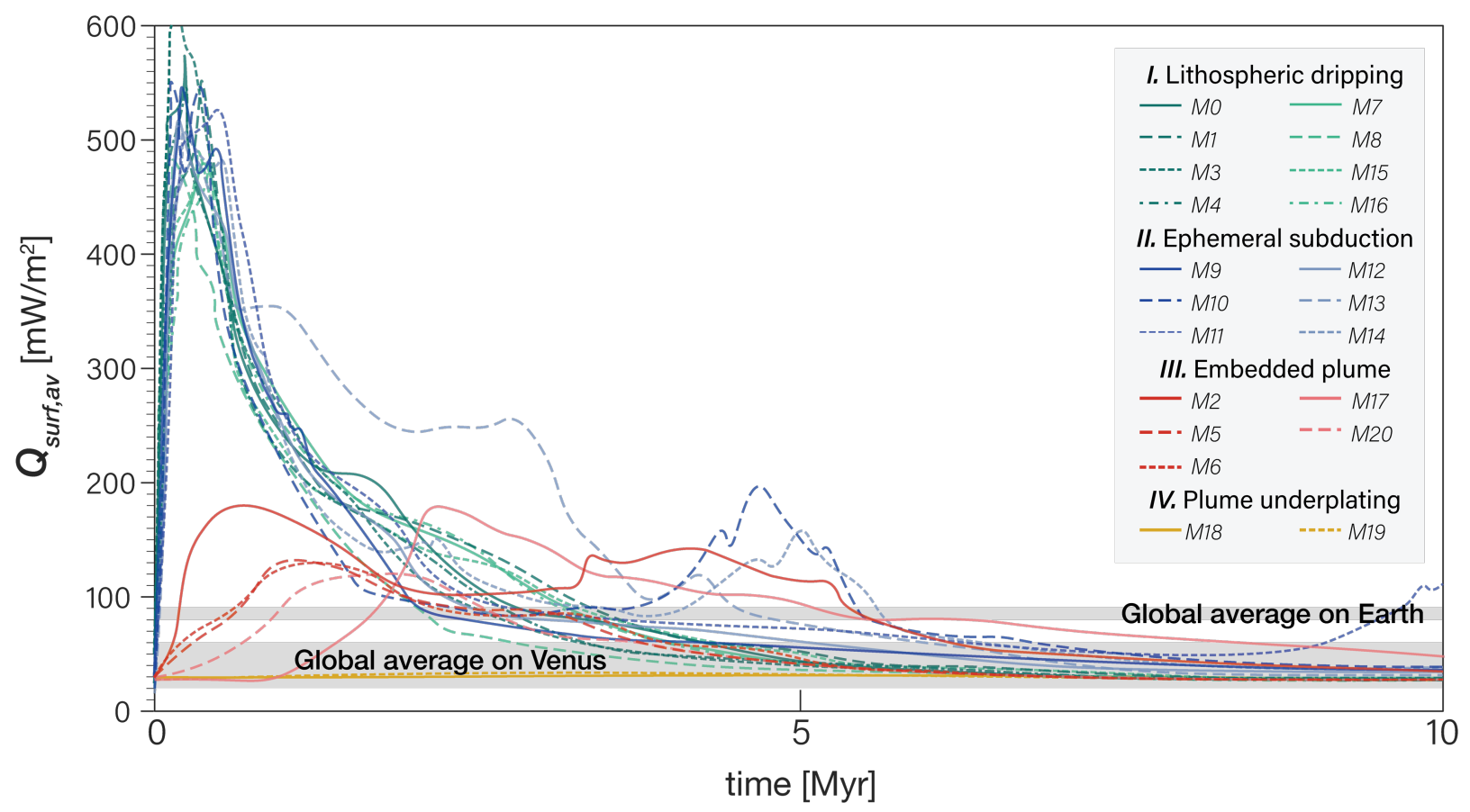

Extended Data Figure 8 - Averaged corona surface heat flow over time (first 10 Myr of model evolution) for all numerical models in this study. Color coding is accordingly to the regime the numerical models are categorized (see main text and Figure 3). More detail on the calculation of the averaged corona surface heat flow can be found in Methods. Peak heat flow reaches 500$600 \mathrm{~mW} / \mathrm{m}^{2}$ (plume penetrating regimes); $200 \mathrm{~mW} / \mathrm{m}^{2}$ (embedded plume regime), or $\sim 50$ $\mathrm{mW} / \mathrm{m}^{2}$ (for underplated plume), but decreases significantly following peak activity. 


\begin{tabular}{|c|c|c|c|c|}
\hline Material & $\begin{array}{l}\text { Initial density } \rho_{0} \\
{\left[\mathrm{~kg} / \mathrm{m}^{3}\right]}\end{array}$ & $\begin{array}{c}\text { Thermal } \\
\text { conductivity } \kappa \\
{[\mathrm{W} /(\mathrm{m} \cdot \mathrm{K})]}\end{array}$ & Rheology & $\begin{array}{c}H_{\mathrm{r}} \\
{\left[\mu \mathrm{W} / \mathrm{m}^{3}\right]}\end{array}$ \\
\hline & & & Wet quartzite flow law ${ }^{a}$ : & \\
\hline $\begin{array}{l}\text { Upper crust } \\
\text { (basalt) }\end{array}$ & $\begin{array}{c}3000 \text { (solid) } \\
2900 \text { (molten) }\end{array}$ & $1.18+\frac{474}{(T+77)}$ & $\begin{array}{l}A_{\mathrm{d}}=1.97 \cdot 10^{17}, n=2.3 \\
E=154 \mathrm{~kJ} / \mathrm{mol}, V=0 \mathrm{~J} / \mathrm{mol} / \mathrm{MPa}, \\
\sigma_{\mathrm{cr}}=3 \cdot 10^{4} \mathrm{~Pa}, C=0.3 \mathrm{MPa}, \varphi_{0}=0.2 \\
\text { Plagioclase An75 flow law }{ }^{a}:\end{array}$ & 0.25 \\
\hline $\begin{array}{l}\text { Lower crust } \\
\text { (gabbro) }\end{array}$ & $\begin{array}{c}3000 \text { (solid) } \\
2900 \text { (molten) }\end{array}$ & $1.18+\frac{474}{(T+77)}$ & $\begin{array}{l}A_{\mathrm{d}}=14.80 \cdot 10^{17}, n=3.2, \\
E=238 \mathrm{~kJ} / \mathrm{mol}, V=0 \mathrm{~J} / \mathrm{mol} / \mathrm{MPa}, \\
\sigma_{\mathrm{cr}}=3 \cdot 10^{4} \mathrm{~Pa}, C=0.3 \mathrm{MPa}, \varphi_{0}=0.2 \\
\text { Plagioclase An75 flow law }{ }^{a}:\end{array}$ & 0.25 \\
\hline $\begin{array}{l}\text { Newly formed } \\
\text { crust }\end{array}$ & $\begin{array}{c}3000 \text { (solid) } \\
2900 \text { (molten) }\end{array}$ & $1.18+\frac{474}{(T+77)}$ & $\begin{array}{l}A_{\mathrm{d}}=14.80 \cdot 10^{17}, n=3.2, \\
E=238 \mathrm{~kJ} / \mathrm{mol}, V=0 \mathrm{~J} / \mathrm{mol} / \mathrm{MPa}, \\
\sigma_{\mathrm{cr}}=3 \cdot 10^{4} \mathrm{~Pa}, C=0.3 \mathrm{MPa}, \varphi_{0}=0.2 \\
\text { Dry olivine flow law }{ }^{a}:\end{array}$ & 0.25 \\
\hline $\begin{array}{l}\text { Lithospheric } \\
\text { mantle/ } \\
\text { Asthenosphere }\end{array}$ & $\begin{array}{c}3300 \text { (solid) } \\
2900 \text { (molten) }\end{array}$ & $0.73+\frac{1293}{(T+77)}$ & $\begin{array}{l}A_{\mathrm{d}}=3.98 \cdot 10^{18}, n=3.5 \\
E=532 \mathrm{~kJ} / \mathrm{mol}, V=8 \mathrm{~J} / \mathrm{mol} / \mathrm{MPa}, \\
\sigma_{\mathrm{cr}}=3 \cdot 10^{4} \mathrm{~Pa}, C=0.3 \mathrm{MPa}, \varphi_{0}=0.2\end{array}$ & 0.022 \\
\hline
\end{tabular}

Extended Data Table 1 - Physical properties of rock materials used in the numerical experiments. $A_{d}$ is the material constant, $n$ is the stress exponent parameter, $E$ and $V$ represent activation energy and volume, respectively, $\sigma_{c r}$ is the diffusion-dislocation creep transition stress, $C$ is material cohesion, $\varphi_{0}$ is the internal friction coefficient and $H_{r}$ is the constant radioactive heating of the material. ${ }^{a}$ Flow law for all materials based on Ranalli ${ }^{58}$. 


\begin{tabular}{|c|c|c|c|c|c|c|c|c|c|}
\hline $\begin{array}{c}\text { Model } \\
\mathrm{nr}\end{array}$ & $\begin{array}{l}\text { Plume } \\
\text { width, } \\
\text { height } \\
{[\mathrm{km}]}\end{array}$ & $\begin{array}{c}\text { Plume } \\
\text { temperature } \\
{[\mathrm{K}]}\end{array}$ & $\begin{array}{c}\text { Plate } \\
\text { cooling age; } \\
\text { thickness } \\
\text { [Ma; km] }\end{array}$ & $\begin{array}{c}\text { Crustal } \\
\text { thickness } \\
\text { [km] }\end{array}$ & $\begin{array}{c}\text { Moho } \\
\text { temperature } \\
{[\mathrm{K}]}\end{array}$ & $\lambda_{\text {melt }, 0}$ & $\begin{array}{r}f_{\text {melt, }} \\
{[\mathrm{m} / \mathrm{s}]}\end{array}$ & $\begin{array}{c}\text { Buoyancy } \\
\text { ratio } \\
\mathrm{Br}\end{array}$ & Regime \\
\hline $\mathrm{MO}^{\mathrm{a}}$ & $260 ; 260$ & 1888 & $40 ; 45$ & 30 & 1129 & 0.01 & $10^{-10}$ & 7.81 & I \\
\hline M1 & $260 ; 260$ & 1838 & $40 ; 45$ & 30 & 1129 & 0.01 & $10^{-10}$ & 5.76 & I \\
\hline M2 & $260 ; 260$ & 1788 & $40 ; 45$ & 30 & 1129 & 0.01 & $10^{-10}$ & 3.70 & III \\
\hline M3 & $500 ; 260$ & 1888 & $40 ; 45$ & 30 & 1129 & 0.01 & $10^{-10}$ & 12.09 & 1 \\
\hline$M 4^{b}$ & $180 ; 180$ & 1888 & $40 ; 45$ & 30 & 1129 & 0.01 & $10^{-10}$ & 5.98 & I \\
\hline M5 & $100 ; 100$ & 1888 & $40 ; 45$ & 30 & 1129 & 0.01 & $10^{-10}$ & 3.64 & III \\
\hline M6 & $100 ; 100$ & 1888 & $40 ; 45$ & 30 & 1129 & 0.01 & $10^{-10}$ & 3.64 & III \\
\hline$M 7^{b}$ & $180 ; 180$ & 1838 & $40 ; 45$ & 30 & 1129 & 0.01 & $10^{-10}$ & 4.56 & I \\
\hline M8 & $260 ; 260$ & 1888 & $40 ; 45$ & 45 & 1286 & 0.01 & $10^{-10}$ & 8.05 & I \\
\hline M9 & $260 ; 260$ & 1888 & $40 ; 45$ & 15 & 946 & 0.01 & $10^{-10}$ & 7.60 & II \\
\hline M10 & $260 ; 260$ & 1888 & $80: 65$ & 30 & 1026 & 0.01 & $10^{-10}$ & 5.50 & II \\
\hline M11 & $260 ; 260$ & 1888 & $120 ; 80$ & 30 & 978 & 0.01 & $10^{-10}$ & 4.50 & II \\
\hline M12 & $260 ; 260$ & 1888 & $120 ; 80$ & 45 & 1090 & 0.01 & $10^{-10}$ & 4.57 & II \\
\hline M13 & $260 ; 260$ & 1888 & $120 ; 80$ & 15 & 859 & 0.01 & $10^{-10}$ & 4.42 & II \\
\hline M14 & $260 ; 260$ & 1888 & $80 ; 65$ & 15 & 884 & 0.01 & $10^{-10}$ & 5.39 & II \\
\hline M15 & $260 ; 260$ & 1888 & $80 ; 65$ & 45 & 1155 & 0.01 & $10^{-10}$ & 5.61 & I \\
\hline M16 & $260 ; 260$ & 1888 & $40 ; 45$ & 30 & 1129 & 0.02 & $10^{-10}$ & 4.13 & I \\
\hline M17 & $260 ; 260$ & 1838 & $40 ; 45$ & 30 & 1129 & 0.02 & $10^{-10}$ & 3.04 & III \\
\hline M18 & $260 ; 260$ & 1838 & $40 ; 45$ & 30 & 1129 & 0.01 & $10^{-7}$ & 0.52 & IV \\
\hline $\mathrm{M} 19^{c}$ & $100 ; 100$ & 1888 & $40 ; 45$ & 15 & 946 & 0.01 & $10^{-10}$ & 3.54 & IV \\
\hline $\mathrm{M} 20^{c}$ & $100 ; 100$ & 1888 & $40 ; 45$ & 45 & 1286 & 0.01 & $10^{-10}$ & 3.75 & III \\
\hline
\end{tabular}

Extended Data Table 2 -Summary of the conditions and results of the numerical experiments.

All models, except those noted differently, have a resolution of $5 \times 2 \times 5 \mathrm{~km}^{3}(x \cdot y \cdot z)$. Note that the plate thickness is a rounded value. a Reference model, ${ }^{b}$ Increased resolution of $3 \times 2 \times 3 \mathrm{~km}^{3},{ }^{c}$ Increased resolution of $2.5 \times 1.5 \times 2.5 \mathrm{~km}^{3}$. Regime I: plume penetration followed by lithospheric dripping and a final topographic inversion once plume activity ceases. Regime II: plume penetration followed by ephemeral subduction at the plume margin and a final topographic inversion once plume activity ceases. Regime III: partial penetration of the plume into the lithosphere that becomes embedded underneath it (transitional regime). Regime IV: plume underplating (see Fig. 3 and Extended Data Fig. 4). 